\title{
Titanium Pnictide Oxide Superconductors
}

\author{
Takeshi Yajima \\ Institute for Solid State Physics, The University of Tokyo, Kashiwa, Chiba 277-8581, Japan; \\ yajima@issp.u-tokyo.ac.jp; Tel.: +81-4-7136-3461 \\ Academic Editor: Yoshikazu Mizuguchi \\ Received: 1 December 2016; Accepted: 3 January 2017; Published: 12 January 2017
}

\begin{abstract}
In 2012, a novel superconductor $\mathrm{BaTi}_{2} \mathrm{Sb}_{2} \mathrm{O}$ was found in the layered titanium pnictide oxides $A \mathrm{Ti}_{2} \mathrm{Pn}_{2} \mathrm{O}$. A related superconductor $\mathrm{BaTi}_{2} \mathrm{Bi}_{2} \mathrm{O}$ was subsequently discovered in 2013. The structure of these materials consists of alternate stacking of superconducting $\mathrm{Ti}_{2} \mathrm{Pn}_{2} \mathrm{O}$ layers and Ba blocking layers, which is somewhat similar to high- $T_{c}$ cuprates since the $\mathrm{Ti}_{2} \mathrm{Pn}_{2} \mathrm{O}$ layer contains an anti-CuO $\mathrm{Cu}_{2}$-type $\mathrm{Ti}_{2} \mathrm{O}$ square lattice. In addition to the structural similarity to the well-known high- $T_{\mathrm{c}}$ superconductors, $\mathrm{BaTi}_{2} \mathrm{Pn}_{2} \mathrm{O}$ shows unique physical properties: two superconducting domes appear in the electronic phase diagram for solid solutions of $\mathrm{BaTi}_{2}\left(\mathrm{Sb}_{1-x} \mathrm{Bi}_{x}\right)_{2} \mathrm{O}$ and a unique density-wave instability which coexists with superconductivity. In this short review, the early studies of titanium pnictide oxides, the discovery of novel superconductors $\mathrm{BaTi}_{2} \mathrm{Pn}_{2} \mathrm{O}$, and recent progress are summarized.
\end{abstract}

Keywords: titanium pnicide oxides; superconductivity; density-wave; $d^{1}$ square lattice; mixed anion compounds; two-dome structure in $T_{\mathrm{C}}$

\section{Introduction}

The discovery and the extensive studies of exotic superconductors have given rise to new classes of superconductors. The high- $T_{\mathrm{c}}$ superconductivity in cuprates has led to enormous interests in layered materials, and several classes of layered superconductors have been found mainly in light-element-based intermetallics (e.g., $\mathrm{MgB}_{2}$ ) and transition metal oxides (e.g., $\mathrm{Sr}_{2} \mathrm{RuO}_{4}$ ) [1-5]. The superconductivity in the Fe-based layered pnictides/chalcogenides is one of the intriguing discoveries in this trend, and it has triggered a surge of interest in materials containing relatively heavy elements like pnictogen [6]. Following the iron pnictides/chalcogenides, various kinds of superconductors have been discovered in pnictides and chalcogenides, such as $\mathrm{BiS}_{2}$-based superconductors [7-10]. The titanium pnictide oxide $\mathrm{BaTi}_{2} \mathrm{Pn}_{2} \mathrm{O}(\mathrm{Pn}=\mathrm{Sb}, \mathrm{Bi})$ is one of the new classes of these superconductors.

The first members of titanium pnictide oxides are $\mathrm{Na}_{2} \mathrm{Ti}_{2} \mathrm{Pn}_{2} \mathrm{O}(\mathrm{Pn}=\mathrm{As}, \mathrm{Sb})$, which were found in 1990 and show the anomaly in resistivity and magnetic susceptibility reminiscent of a charge-density-wave (CDW) or spin-density-wave (SDW) [11]. The unconventional superconductivity has often been found in the vicinity of other ordered phases such as CDW, SDW, and antiferromagnetic phase $[6,12,13]$. Hence, the titanium pnictide oxides have been considered as good candidates of the playground for exotic superconductivity due to their density-wave (DW) states. The titanium pnictide oxides have also attracted attention due to their similarity to the cuprates. $\mathrm{Na}_{2} \mathrm{Ti}_{2} \mathrm{Pn}_{2} \mathrm{O}$ crystallizes in a so-called anti- $\mathrm{K}_{2} \mathrm{NiF}_{4}$-type layered structure: it consists of an alternate stacking of double layers of $\mathrm{Na}$ and $\mathrm{Ti}_{2} \mathrm{Pn}_{2} \mathrm{O}$ layers. The $\mathrm{Ti}_{2} \mathrm{Pn}_{2} \mathrm{O}$ layer has an anti-CuO${ }_{2}$-type $\mathrm{Ti}_{2} \mathrm{O}$ square lattice where $\mathrm{Ti}^{3+}\left(d^{1}\right)$ is coordinated by two oxide anions and four pnictide anions. The square lattice can be regarded as an anti-configuration of the $\mathrm{CuO}_{2}\left(d^{9}\right)$ square lattice.

The discovery of superconductivity in iron pnictides brought renewed attention in titanium pnictide oxides, and several novel compounds have been found in this family. In 2012, we discovered 
a novel layered superconductor $\mathrm{BaTi}_{2} \mathrm{Sb}_{2} \mathrm{O}\left(T_{\mathrm{c}}=1.2 \mathrm{~K}\right)$, and subsequently $\mathrm{BaTi}_{2} \mathrm{Bi}_{2} \mathrm{O}\left(T_{\mathrm{c}}=4.6 \mathrm{~K}\right)$ in $2013[14,15]$. These titanium pnictide oxides $\mathrm{BaTi}_{2} \mathrm{Pn}_{2} \mathrm{O}(\mathrm{Pn}=\mathrm{Sb}, \mathrm{Bi})$ consist of superconducting $\mathrm{Ti}_{2} \mathrm{Pn}_{2} \mathrm{O}$ layers and Ba blocking layers. At present, eight titanium pnictide oxides $\mathrm{Na}_{2} \mathrm{Ti}_{2} P n_{2} \mathrm{O}$ $(P n=\mathrm{As}, \mathrm{Sb}),(\mathrm{SrF})_{2} \mathrm{Ti}_{2} P n_{2} \mathrm{O}(P n=\mathrm{As}, \mathrm{Sb}, \mathrm{Bi})$, and $\mathrm{BaTi}_{2} P n_{2} \mathrm{O}(P n=\mathrm{As}, \mathrm{Sb}, \mathrm{Bi})$ have been synthesized, but only $\mathrm{BaTi}_{2} \mathrm{Pn}_{2} \mathrm{O}(\mathrm{Pn}=\mathrm{Sb}, \mathrm{Bi})$ shows superconductivity [11,14-17]. Though $\mathrm{BaTi}_{2} P n_{2} \mathrm{O}$ is not high- $T_{\mathrm{c}}$ superconductor, several unique and attracting physical properties have been found: two superconducting domes in the phase diagram of isovalent solid solutions of $\mathrm{BaTi}_{2}\left(\mathrm{Sb}_{1-x} \mathrm{Bi}_{x}\right)_{2} \mathrm{O}$ and unconventional DW instability [18,19]. In this short review, the superconductivity and DW instability in the titanium pnictide oxides will be discussed from discovery to recent progress.

\section{Road to the Discovery of Superconductivity in Titanium Pnictide Oxides}

We have been interested in the mixed anion compounds, such as oxyhydrides, oxyfluorides, and oxynitrides. The coexistence of multiple anions with different valences, ionic radii, electronegativities, and atomic polarizabilities in the structure provide great opportunities to realize unique electronic properties beyond the single anion coordination system, such as oxides. Hence, we initially focused on the titanium pnictide oxides in terms of their unique coordination environment discussed below. In this section, crystal structures and early studies of titanium pnictide oxides will be summarized as a background to the discovery of superconductivity in $\mathrm{BaTi}_{2} \mathrm{Sb}_{2} \mathrm{O}$ and $\mathrm{BaTi}_{2} \mathrm{Bi}_{2} \mathrm{O}$.

\subsection{Crystal Structure of $A T i_{2} \mathrm{Pn}_{2} \mathrm{O}\left(A=B a, N a_{2},(S r F)_{2} ; \mathrm{Pn}=A s, \mathrm{Sb}\right)$}

The titanium pnictide oxides $A \mathrm{Ti}_{2} \mathrm{Pn}_{2} \mathrm{O}$ crystallize in a tetragonal cell with stacked $\mathrm{Ti}_{2} \mathrm{Pn}_{2} \mathrm{O}$ layers and blocking layers $A\left(A=\mathrm{Ba}, \mathrm{Na}_{2},(\mathrm{SrF})_{2}\right)$. In Figure 1 the crystal structures of titanium pnictide oxides with three types of blocking layers are shown where the space group of these compounds are $I 4 / \mathrm{mmm}$ $\left(A=\mathrm{Na}_{2},(\mathrm{SrF})_{2}\right)$ or $\mathrm{P} 4 / \mathrm{nmm}(A=\mathrm{Ba})$. The structure is somewhat similar to cuprates, in particular $\mathrm{La}_{2} \mathrm{CuO}_{4}\left(\mathrm{~K}_{2} \mathrm{NiF}_{4}\right.$ type structure): $A \mathrm{Ti}_{2} \mathrm{Pn}_{2} \mathrm{O}$ has a $\mathrm{Ti}_{2} \mathrm{O}$ square lattice, which is an anti-configuration to the $\mathrm{CuO}_{2}$ square lattice in cuprates. The structure of $\mathrm{Na}_{2} \mathrm{Ti}_{2} \mathrm{Pn}_{2} \mathrm{O}$ can be viewed as an anti-K $\mathrm{K}_{2} \mathrm{NiF}_{4}$ type structure where $\mathrm{Na}, \mathrm{Ti}, \mathrm{Pn}$, and $\mathrm{O}$, respectively, occupy apical $\mathrm{F}$ site, equatorial $\mathrm{F}$ site, $\mathrm{K}$ site, and $\mathrm{Ni}$ site. In $\mathrm{Ti}_{2} \mathrm{O}$ square lattice, the formal oxidation state of Ti is trivalent $\left(d^{1}\right)$, which is electron-hole symmetric to that of $\mathrm{Cu}\left(d^{9}\right)$ in cuprates. After the discovery of high- $T_{\mathrm{c}}$ in cuprates, $d^{1}$ analogues of cuprates, such as $\mathrm{Sr}_{2} \mathrm{VO}_{4}$, have been investigated to realize an electronic structure similar to that of cuprates [20]. In addition to the absence of superconductivity in these compounds, theoretical study suggested the splitting of the $t_{2 \mathrm{~g}}$ orbital in these compounds is much smaller than that of the $e_{\mathrm{g}}$ orbital in cuprates, resulting in these $d^{1}$ analogues not showing a half-filled single band system in contrast to cuprates [21]. In titanium pnictide oxides, the Ti atoms are octahedrally coordinated by two oxide anions and four pnitide anions. Such a mixed anionic coordination provides a unique opportunity for the $t_{2 \mathrm{~g}}$ orbitals to split to a greater extent than that of a single anionic coordination system, such as $M_{6}(M=$ transition metal $)$ octahedra in oxides as discussed above. Thus, the titanium pnictide oxides might be a possible candidate for the $d^{1}$ analogue of cuprates reflecting the mixed anionic coordination. Note that, as discussed later, theoretical studies revealed the crystal field of the $\mathrm{TiO}_{2} P n_{4}$ octahedron has indeed removed the degeneracy of $t_{2 \mathrm{~g}}$ orbital, but three $d$ orbitals still contribute significantly to the density of states (DOS) at the Fermi level.

The discovery of superconductivity in iron pnictides and chalcogenides has triggered to a remarkable interest and extensive studies of exploring novel superconductors in layered pnictides and chalcogenides. In Fe-based superconductors, several structural types have been found such as $R E F$ AsO $(R E=$ rare earth) and $A E F e A s F(A E=$ alkaline earth $)$ with ZrCuSiAs-type structure, $A E \mathrm{Fe}_{2} \mathrm{As}_{2}$ with $\mathrm{ThCr}_{2} \mathrm{Si}_{2}$-type structure, $A \mathrm{FeAs}(A=$ alkali) with $\mathrm{PbClF} / \mathrm{Cu}$ Sb-type structure, and FeCh ( $C h=$ chalcogenides) with PbO-type structure. The difference of these structural types is mainly a blocking layer. The crystal structure of $\mathrm{Na}_{2} \mathrm{Ti}_{2} \mathrm{Pn}_{2} \mathrm{O}$ consists of alternate stacking of double Na layers and $\mathrm{Ti}_{2} \mathrm{Pn}_{2} \mathrm{O}$ layers, which is similar to that of $A$ FeAs in that double $A$ layers and the conducting layer $\left(\mathrm{Ti}_{2} \mathrm{Pn}_{2} \mathrm{O}\right.$ or FeAs layer) are alternatively stacked. Hence, inspired by these structural types in 
Fe-based superconductors, new families of titanium pnictide oxides $\left(\mathrm{SrF}_{2} \mathrm{Ti}_{2} \mathrm{Pn}_{2} \mathrm{O}\right.$ and $\mathrm{BaTi}_{2} \mathrm{As}_{2} \mathrm{O}$, where double Na layers have been replaced with $(\mathrm{SrF})_{2}$ layers or Ba layers, were found in $2010[14,17]$. In analogy with $\mathrm{Na}_{2} \mathrm{Ti}_{2} \mathrm{Pn}_{2} \mathrm{O}$, the structures of $(\mathrm{SrF})_{2} \mathrm{Ti}_{2} \mathrm{Pn}_{2} \mathrm{O}$ and $\mathrm{BaTi}_{2} \mathrm{As}_{2} \mathrm{O}$ are respectively similar to that of $A E F e A s F(Z r C u S i A s-t y p e)$ and $A E F_{2} A_{2} s_{2}\left(T_{h C r} \mathrm{Si}_{2}\right.$-type) in that they have the same blocking layer $\left(A E \mathrm{~F}_{2}\right.$ or $A E$ layer).
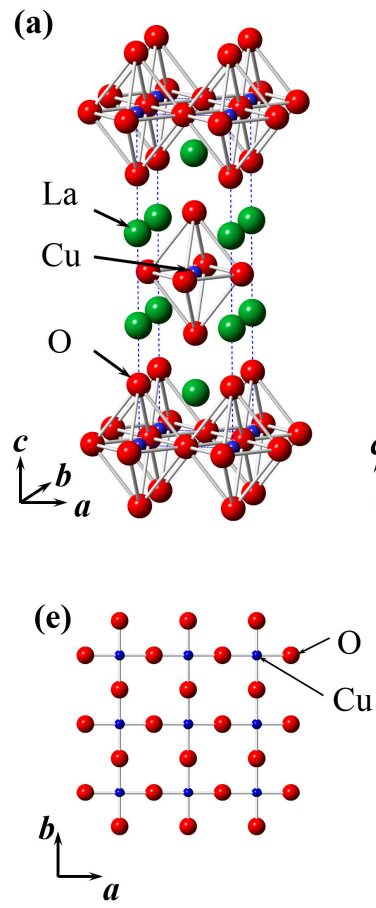

(b)
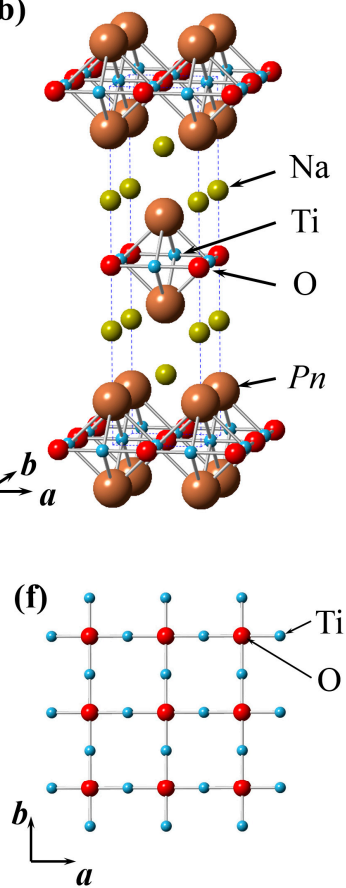

(c)

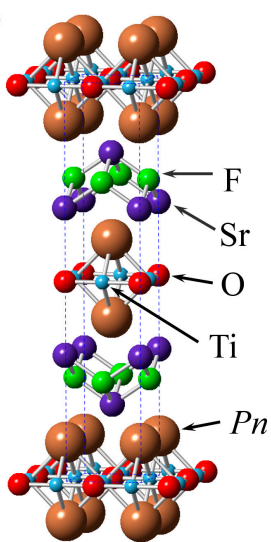

(g)

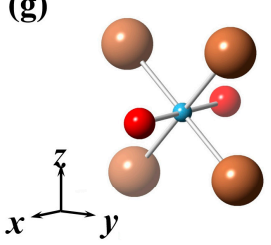

(d)

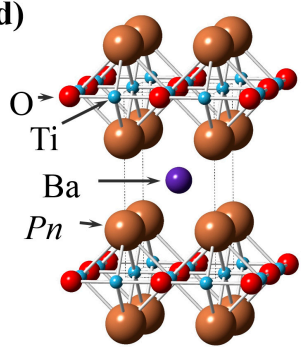

(h)

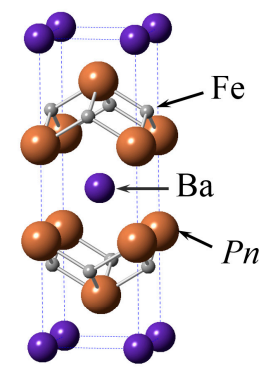

Figure 1. Crystal structure of (a) $\mathrm{La}_{2} \mathrm{CuO}_{4} ;(\mathbf{b}) \mathrm{Na}_{2} \mathrm{Ti}_{2} \mathrm{Pn}_{2} \mathrm{O}(\mathrm{Pn}=\mathrm{As}, \mathrm{Sb}) ;(\mathbf{c})(\mathrm{SrF})_{2} \mathrm{Ti}_{2} \mathrm{Pn}_{2} \mathrm{O}(\mathrm{Pn}=\mathrm{As}$, $\mathrm{Sb}, \mathrm{Bi}) ;(\mathbf{d}) \mathrm{BaTi}_{2} \mathrm{Pn}_{2} \mathrm{O}(\mathrm{Pn}=\mathrm{As}, \mathrm{Sb}, \mathrm{Bi}) ;(\mathbf{e}) \mathrm{CuO}_{2}$ square lattice in $\mathrm{La}_{2} \mathrm{CuO}_{4} ;$ (f) $\mathrm{Ti}_{2} \mathrm{O}$ square lattice in titanium pnictide oxides; (g) $\mathrm{TiO}_{2} \mathrm{Pn}_{4}$ octahedra in titanium pnictide oxides; (h) crystal structure of $\mathrm{BaFe}_{2} P n_{2}(P n=\mathrm{P}, \mathrm{As})$.

\subsection{Physical Properties of $A T i_{2} \mathrm{Pn}_{2} \mathrm{O}\left(A=B a_{1} \mathrm{Na}_{2},(\mathrm{SrF})_{2} ; \mathrm{Pn}=\mathrm{As}, \mathrm{Sb}\right)$}

$\mathrm{Na}_{2} \mathrm{Ti}_{2} \mathrm{Pn}_{2} \mathrm{O}(\mathrm{Pn}=\mathrm{As}, \mathrm{Sb})$ was first synthesized by Adam et al. in 1990 [11]. These compounds display anomalies in magnetic susceptibility and electrical resistivity at $320 \mathrm{~K}$ and $120 \mathrm{~K}$ for $P n=A s$ and $\mathrm{Sb}$, respectively. Namely, $\mathrm{Na}_{2} \mathrm{Ti}_{2} \mathrm{Pn}_{2} \mathrm{O}$ exhibits a sharp drop in magnetic susceptibility and jump in electrical resistivity as shown in Figure 2 [22]. Above the transition temperature, both compounds show metallic conductivity. The metallic conductivity is also observed below the transition temperature in $\mathrm{Na}_{2} \mathrm{Ti}_{2} \mathrm{Sb}_{2} \mathrm{O}$, whereas $\mathrm{Na}_{2} \mathrm{Ti}_{2} \mathrm{As}_{2} \mathrm{O}$ shows semiconducting behavior. The Sommerfeld constant estimated from specific data is $4.1 \mathrm{~mJ} \cdot \mathrm{mol}^{-1} \cdot \mathrm{K}^{-2}$ and $0 \mathrm{~mJ} \cdot \mathrm{mol}^{-1} \cdot \mathrm{K}^{-2}$ for $\mathrm{Na}_{2} \mathrm{Ti}_{2} \mathrm{Sb}_{2} \mathrm{O}$ and $\mathrm{Na}_{2} \mathrm{Ti}_{2} \mathrm{As}_{2} \mathrm{O}$, respectively, indicating that the densities of states remains finite below the transition temperature in $\mathrm{Na}_{2} \mathrm{Ti}_{2} \mathrm{Sb}_{2} \mathrm{O}$ while $\mathrm{Na}_{2} \mathrm{Ti}_{2} \mathrm{As}_{2} \mathrm{O}$ is fully gapped [23].

The unique crystal structure and the anomalies in the magnetic susceptibility and electrical resistivity have attracted considerable attention, and $\mathrm{Na}_{2} \mathrm{Ti}_{2} \mathrm{Pn}_{2} \mathrm{O}$ have been extensively studied to clarify the origin of the anomaly. Theoretically, Picket suggested the origin of the anomaly is not ferromagnetic/antiferromagnetic ordering but the CDW/SDW instability [24]. Three Fermi surfaces have been found and one of them, a box-shaped Fermi surface around $M$ and $A$ points is almost dispersionless along the $k_{z}$ direction (perpendicular to the $\mathrm{Ti}_{2} \mathrm{O}$ square lattice), resulting in strong nesting of the surface. Biani et al. also found similar Fermi surface nesting and suggested CDW instability is the origin of the anomaly [25]. 

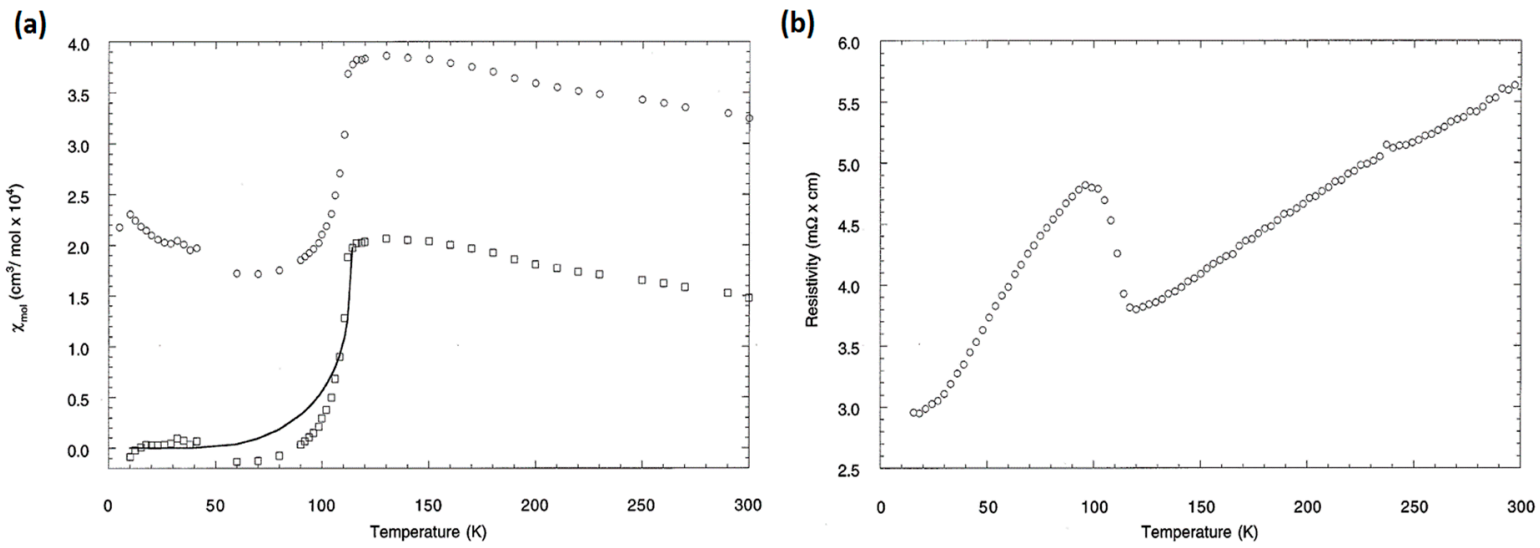

Figure 2. Temperature dependence of (a) magnetic susceptibility under $1 \mathrm{~T}$ and (b) electrical resistivity for $\mathrm{Na}_{2} \mathrm{Ti}_{2} \mathrm{Sb}_{2} \mathrm{O}$. Reprinted with permission from Axtell et al., J. Solid State Chem; published by Elsevier, 1997 [22].

In the low-temperature powder neutron diffraction studies the structural distortion is observed at around $120 \mathrm{~K}$ : with a decrease in the temperature, the lattice is elongated along the $a$-axis but contracted along the $c$-axis around $120 \mathrm{~K}$, which leads to distortion of $\mathrm{TiO}_{2} \mathrm{Pn}_{4}$ octrahedra, where the Ti-O bond is elongated and the Ti-Pn bond is shortened (Figure 3a) [26]. This indicates the anomaly observed in susceptibility and resistivity is accompanied with structural distortion. CDW/SDW compounds generally show a periodic structural modulation below the transition temperature. However, in $\mathrm{Na}_{2} \mathrm{Ti}_{2} \mathrm{Sb}_{2} \mathrm{O}$, no peaks derived from magnetic ordering or the superlattice have been found in the low-temperature powder neutron diffraction data. Note that the neutron diffraction experiments do not exclude both CDW and SDW instability at low temperature because it is difficult to discern the modulation in powder neutron diffraction experiments when the modulation is quite small.

(a)

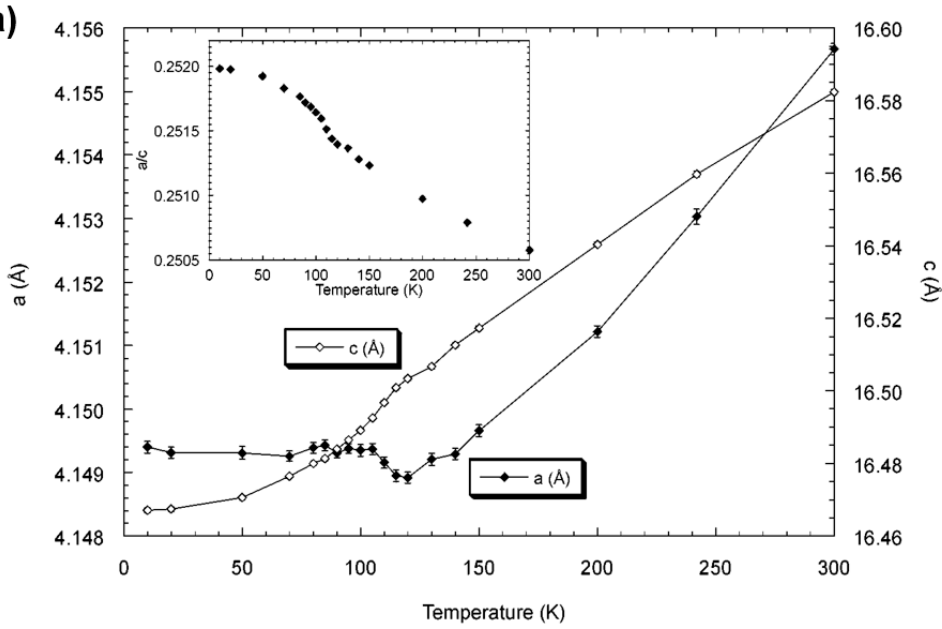

(b)

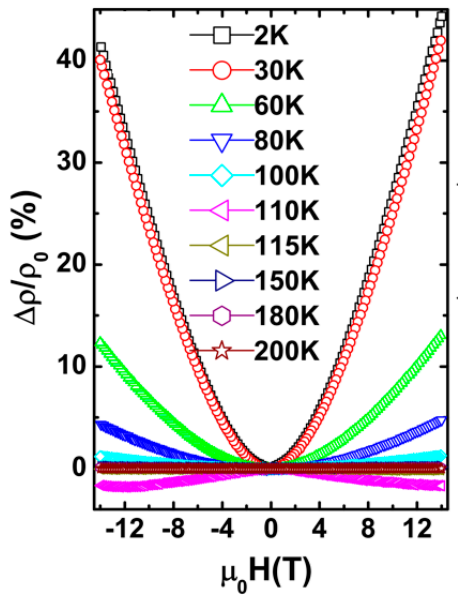

Figure 3. (a) Temperature dependence of lattice parameters for $\mathrm{Na}_{2} \mathrm{Ti}_{2} \mathrm{Sb}_{2} \mathrm{O}$. Reprinted with permission from Ozawa et al., J. Solid State Chem.; published by Elsevier, 2000 [26]. (b) Magnetic field dependence of magnetoresistance for $\mathrm{Na}_{2} \mathrm{Ti}_{2} \mathrm{Sb}_{2} \mathrm{O}$. Reprinted with permission from Liu et al., Phys. Rev. B; published by APS, 2009 [27].

$\mathrm{Na}_{2} \mathrm{Ti}_{2} \mathrm{Sb}_{2} \mathrm{O}$ shows a negative Hall coefficient below $300 \mathrm{~K}$ and a steep rise in the Hall coefficient at around $120 \mathrm{~K}$, indicating that the dominant carrier are electrons and the carrier density decreases below the transition temperature due to the formation of CDW/SDW [23]. A large magnetoresistance (MR), namely $\sim 40 \%$ of MR at $T=2 \mathrm{~K}$ and $H=14 \mathrm{~T}$, has been found in $\mathrm{Na}_{2} \mathrm{Ti}_{2} \mathrm{Sb}_{2} \mathrm{O}$, which has been considered 
as a suppression of SDW instability by the magnetic field (Figure 3b). Thus, no experimental evidence for CDW/SDW instability has been found and the origin of the anomaly has not been unveiled for many years.

In 2004, Ozawa et al. reported single crystal growth of $\mathrm{Na}_{2} \mathrm{Ti}_{2} \mathrm{Sb}_{2} \mathrm{O}$ by using $\mathrm{NaSb}$ flux method [28]. Likewise, single crystal of $\mathrm{Na}_{2} \mathrm{Ti}_{2} \mathrm{As}_{2} \mathrm{O}$ was grown using $\mathrm{NaAs}$ flux by Shi et al. in 2013 [23]. Reflecting the layered structure, $\mathrm{Na}_{2} \mathrm{Ti}_{2} \mathrm{Pn}_{2} \mathrm{O}$ single crystals show anisotropy in electrical resistivity. The ratio of $\rho_{\mathrm{c}} / \rho_{\mathrm{ab}}\left(\gamma_{\rho}\right)$ is $\sim 140$ and $\sim 430$ for $\mathrm{Na}_{2} \mathrm{Ti}_{2} \mathrm{Sb}_{2} \mathrm{O}$ and $\mathrm{Na}_{2} \mathrm{Ti}_{2} \mathrm{As}_{2} \mathrm{O}$, whereas an anisotropy of less than a factor of 2 for $\mathrm{Na}_{2} \mathrm{Ti}_{2} \mathrm{Sb}_{2} \mathrm{O}$ is theoretically suggested [24]. These values of $\gamma_{\rho}$ are much larger than that of iron arsenide LiFeAs $\left(\gamma_{\rho} \sim 1.3-3.3\right)$ [29], which has an alikali double layer like $\mathrm{Na}_{2} \mathrm{Ti}_{2} P n_{2} \mathrm{O}$. Note that $\gamma_{\rho}$-values for iron arsenides with a different blocking layer have also been reported such as $\gamma_{\rho} \sim 1-6$ for $A E \mathrm{Fe}_{2} \mathrm{As}_{2}$ [30] and $\gamma_{\rho} \sim 20-200$ for $\mathrm{LaFeAsO}$ [31]. From the structural point of view, $\mathrm{Na}_{2} \mathrm{Ti}_{2} \mathrm{Sb}_{2} \mathrm{O}$ is expected to have a more two-dimensional nature (stronger anisotropy) than $\mathrm{Na}_{2} \mathrm{Ti}_{2} \mathrm{As}_{2} \mathrm{O}$, since the interlayer distance of $\mathrm{Na}_{2} \mathrm{Ti}_{2} \mathrm{Sb}_{2} \mathrm{O}$ is larger than that of $\mathrm{Na}_{2} \mathrm{Ti}_{2} \mathrm{As}_{2} \mathrm{O}$ (see Table 1). The weaker anisotropy in $\mathrm{Na}_{2} \mathrm{Ti}_{2} \mathrm{Sb}_{2} \mathrm{O}$ is possibly ascribed to the hybridization of the Pn- $p$ orbital and the Ti-3d orbital, as theoretically suggested [32]. The replacement of As with Sb having a higher energy level than As leads to stronger hybridization with the Ti-3d orbital because the Pn- $p$ orbital has a lower energy level than the Ti-3d orbital, resulting in the weakening of the anisotropy.

Table 1. Cell parameters and transition temperature of DW $\left(T_{\mathrm{DW}}\right)$ and superconductivity $\left(T_{\mathrm{c}}\right)$.

\begin{tabular}{|c|c|c|c|c|c|c|c|}
\hline Compound & Space Group & $a(\AA)$ & $c(\AA)$ & $\begin{array}{c}\text { Interlayer Distance } \\
d(\AA)\end{array}$ & $T_{\mathrm{DW}}(\mathrm{K})$ & $T_{\mathrm{c}}(\mathrm{K})$ & Ref. \\
\hline $\mathrm{Na}_{2} \mathrm{Ti}_{2} \mathrm{As}_{2} \mathrm{O}$ & $\mathrm{I} / \mathrm{mmm}$ & $4.070(2)$ & $15.288(4)$ & 7.644 & 320 & $\mathrm{~N} / \mathrm{A}$ & [11] \\
\hline $\mathrm{Na}_{2} \mathrm{Ti}_{2} \mathrm{Sb}_{2} \mathrm{O}$ & $I 4 / \mathrm{mmm}$ & $4.144(1)$ & 16.561(1) & 8.281 & 120 & $\mathrm{~N} / \mathrm{A}$ & [11] \\
\hline$(\mathrm{SrF})_{2} \mathrm{Ti}_{2} \mathrm{As}_{2} \mathrm{O}$ & $I 4 / \mathrm{mmm}$ & $4.04865(5)$ & $19.4204(2)$ & 9.7102 & 380 & $\mathrm{~N} / \mathrm{A}$ & [17] \\
\hline$(\mathrm{SrF})_{2} \mathrm{Ti}_{2} \mathrm{Sb}_{2} \mathrm{O}$ & $\mathrm{I} / \mathrm{mmm}$ & 4.1095(1) & $20.8858(5)$ & 10.4429 & 200 & $\mathrm{~N} / \mathrm{A}$ & [17] \\
\hline$(\mathrm{SrF})_{2} \mathrm{Ti}_{2} \mathrm{Bi}_{2} \mathrm{O}$ & $I 4 / \mathrm{mmm}$ & $4.11782(2)$ & $21.3703(2)$ & 10.68515 & $\mathrm{~N} / \mathrm{A}$ & $\mathrm{N} / \mathrm{A}$ & [16] \\
\hline $\mathrm{BaTi}_{2} \mathrm{As}_{2} \mathrm{O}$ & $\mathrm{P} 4 / \mathrm{nmm}$ & $4.047(3)$ & $7.275(4)$ & 7.275 & 200 & $\mathrm{~N} / \mathrm{A}$ & [14] \\
\hline $\mathrm{BaTi}_{2} \mathrm{Sb}_{2} \mathrm{O}$ & $\mathrm{P} 4 / \mathrm{nmm}$ & $4.11039(2)$ & $8.08640(4)$ & 8.0864 & 50 & 1.2 & [15] \\
\hline $\mathrm{BaTi}_{2} \mathrm{Bi}_{2} \mathrm{O}$ & $\mathrm{P} 4 / \mathrm{nmm}$ & $4.12316(4)$ & $8.3447(1)$ & 8.3447 & $\mathrm{~N} / \mathrm{A}$ & 4.6 & [16] \\
\hline
\end{tabular}

Similar anomalies in magnetic susceptibility and electrical resistivity have also been found in other members of titanium pnictide oxides, $(\mathrm{SrF})_{2} \mathrm{Ti}_{2} \mathrm{Pn}_{2} \mathrm{O}$ and $\mathrm{BaTi}_{2} \mathrm{As}_{2} \mathrm{O}$ [14,17]. With decreasing temperature, a metal-to-semiconductor transition is clearly observed in the resistivity at around $200 \mathrm{~K}$ for $(\mathrm{SrF})_{2} \mathrm{Ti}_{2} \mathrm{Sb}_{2} \mathrm{O}$ and $380 \mathrm{~K}$ for $(\mathrm{SrF})_{2} \mathrm{Ti}_{2} \mathrm{As}_{2} \mathrm{O}$, respectively, indicating these compounds are fully gapped below the transition temperature, as observed in $\mathrm{Na}_{2} \mathrm{Ti}_{2} \mathrm{As}_{2} \mathrm{O}$ (Figure 4a). The magnetic susceptibility shows a sharp drop at almost the same temperature as the resistive anomaly (Figure $4 \mathrm{~b}$ ). $(\mathrm{SrF})_{2} \mathrm{Ti}_{2} \mathrm{Sb}_{2} \mathrm{O}$ shows a negative Hall coefficient above the density-wave transition temperature $T_{\mathrm{DW}}$ and a steep rise of the Hall coefficient around the $T_{\mathrm{DW}}$, indicating the dominant carrier are electrons and the decrease in the carrier density at $T_{\mathrm{DW}}$ is due to the opening gap. The Seebeck coefficient for $(\mathrm{SrF})_{2} \mathrm{Ti}_{2} \mathrm{Sb}_{2} \mathrm{O}$ is negative above $T_{\mathrm{DW}}$ and changes its sign from negative to positive below $T_{\mathrm{DW}}$ with decreasing temperature, indicating multicarrier conduction in this compound. The temperature dependences of the lattice parameters $a$ and $c$, obtained by XRD, exhibit a sharp drop in both $a$ and $c$ at the transition temperature, and behavior is different from that observed in $\mathrm{Na}_{2} \mathrm{Ti}_{2} \mathrm{Sb}_{2} \mathrm{O}$ (see above). 
(a)

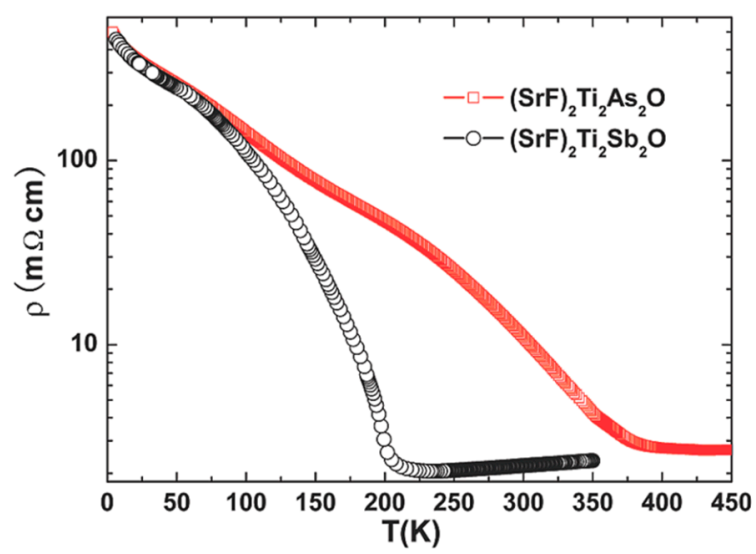

(b)

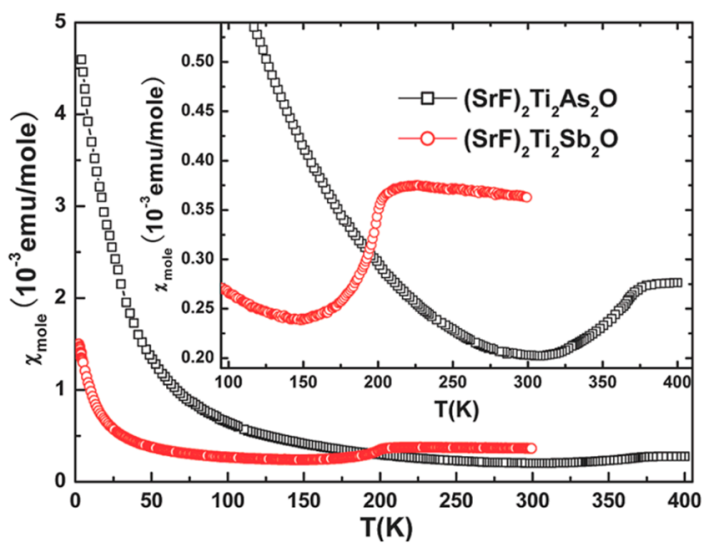

Figure 4. Temperature dependence of (a) electrical resistivity and (b) magnetic susceptibility under $5 \mathrm{~T}$ for $(\mathrm{SrF})_{2} \mathrm{Ti}_{2} \mathrm{Pn}_{2} \mathrm{O}$. Reprinted with permission from Liu et al., Chem. Mater.; published by ACS, 2010 [17].

$\mathrm{BaTi}_{2} \mathrm{As}_{2} \mathrm{O}$ exhibits a sharp drop in magnetic susceptibility at around $200 \mathrm{~K}$ with decreasing temperature, as seen in other titanium pnictide oxides (Figure 5a). However, in contrast to the metal-to-semiconductor transition in $\mathrm{Na}_{2} \mathrm{Ti}_{2} \mathrm{As}_{2} \mathrm{O}$ and $\left(\mathrm{SrF}_{2} \mathrm{Ti}_{2} \mathrm{Pn}_{2} \mathrm{O}, \mathrm{BaTi}_{2} \mathrm{As}_{2} \mathrm{O}\right.$ shows a metal-to-metal transition in electrical resistivity, indicating $\mathrm{BaTi}_{2} \mathrm{As}_{2} \mathrm{O}$ is not fully gapped below $T_{D W}$, as observed in $\mathrm{Na}_{2} \mathrm{Ti}_{2} \mathrm{Sb}_{2} \mathrm{O}$ (Figure $5 \mathrm{~b}$ ). Below the transition temperature, a large MR is observed as seen in $\mathrm{Na}_{2} \mathrm{Ti}_{2} \mathrm{Sb}_{2} \mathrm{O}$. The MR increases with decreasing temperature and reaches $\sim 15 \%$ at $4 \mathrm{~K}$ and $H=14 \mathrm{~T}$. The origin of the MR should be the same as that in $\mathrm{Na}_{2} \mathrm{Ti}_{2} \mathrm{Sb}_{2} \mathrm{O}$, while the MR of $\mathrm{BaTi}_{2} \mathrm{As}_{2} \mathrm{O}$ is smaller than that of $\mathrm{Na}_{2} \mathrm{Ti}_{2} \mathrm{Sb}_{2} \mathrm{O}(\sim 40 \%)$.

(a)

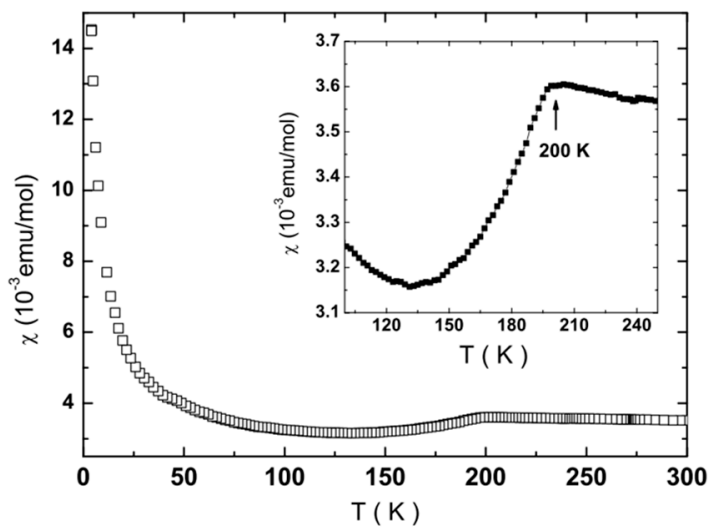

(b)

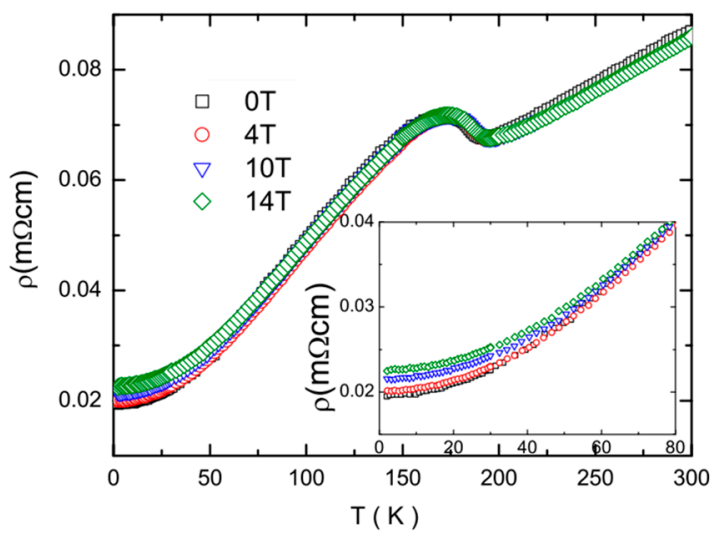

Figure 5. Temperature dependence of (a) magnetic susceptibility under $1 \mathrm{~T}$ and (b) electrical resistivity for $\mathrm{BaTi}_{2} \mathrm{As}_{2} \mathrm{O}$. Reprinted with permission from Wang et al., J. Phys. Condens. Matter.; published by IOP, 2010 [14].

The CDW and SDW instabilities are widely seen in layered compounds, such as transition metal dichalcogenides and iron arsenides. It is generally believed that such a DW state often competes with another electronic state, such as superconductivity, at low temperature. Hence, given the structural similarity to cuprates/iron pnictides and DW transition, titanium pnictide oxides are attractive candidates as novel superconducting materials. The suppression of the CDW/SDW transition has been examined in $\mathrm{BaTi}_{2} \mathrm{As}_{2} \mathrm{O}$ by an intercalation of $\mathrm{Li}^{+}$into the interstitial site, namely $\mathrm{Li}_{x} \mathrm{BaTi}_{2} \mathrm{As}_{2} \mathrm{O}$ [14]. The $T_{\mathrm{DW}}$ decreases and the transition is broadened with increasing $x$, and finally the anomaly is 
smeared out. However, no superconductivity emerges. Note that carrier doping by replacing Ba with $\mathrm{K}, \mathrm{Na}$, La, Sm, Bi, and Al have been tried, but failed. Thus, none of the titanium pnictide oxides shown above exhibits superconductivity.

The lattice parameters and the interlayer distance in titanium pnictide oxides are summarized in Table 1, where the compounds are discussed in later section; namely $\mathrm{BaTi}_{2} \mathrm{Sb}_{2} \mathrm{O}, \mathrm{BaTi}_{2} \mathrm{Bi}_{2} \mathrm{O}$, and $(\mathrm{SrF})_{2} \mathrm{Ti}_{2} \mathrm{Bi}_{2} \mathrm{O}$ are also listed. Reflecting the $I$-centered lattice, the interlayer distance of $A=\mathrm{Na}_{2}$ and $(\mathrm{SrF})_{2}$ compounds is half of the $c$-axis length, while that of $A=\mathrm{Ba}(P$-lattice) is the same as the $c$-axis length. In $(\mathrm{SrF})_{2} \mathrm{Ti}_{2} \mathrm{Pn}_{2} \mathrm{O}$, the $(\mathrm{SrF})_{2}$ blocking layer is bulky, reflecting that the tetrahedral void within the double $\mathrm{Sr}$ layers are filled by additional $\mathrm{F}$ ions, which provides a much longer interlayer distance than that of $\mathrm{Na}_{2} \mathrm{Ti}_{2} P n_{2} \mathrm{O}$ (e.g., $8.281 \AA$ for $\mathrm{Na}_{2} \mathrm{Ti}_{2} \mathrm{Sb}_{2} \mathrm{O}$ vs. $10.4429 \AA$ for $\left.(\mathrm{SrF})_{2} \mathrm{Ti}_{2} \mathrm{Sb}_{2} \mathrm{O}\right)$. In contrast, $\mathrm{BaTi}_{2} \mathrm{Pn}_{2} \mathrm{O}$ has a single Ba layer between $\mathrm{Ti}_{2} \mathrm{Pn}_{2} \mathrm{O}$ layers, resulting in the smallest interlayer distance among the titanium pnictide oxides with the same $P n$. Thus, the interlayer distance decreases in the order of $(\mathrm{SrF})_{2} \mathrm{Ti}_{2} \mathrm{Pn}_{2} \mathrm{O}>\mathrm{Na}_{2} \mathrm{Ti}_{2} \mathrm{Pn}_{2} \mathrm{O}>\mathrm{BaTi}_{2} \mathrm{Pn}_{2} \mathrm{O}$. From Table 1, we can find that $\mathrm{T}_{\mathrm{DW}}$ follows two kinds of trends, namely, $A$ dependence and $P n$ dependence. First, given the same $P n, T_{D W}$ decreases in the order of $(\mathrm{SrF})_{2} \mathrm{Ti}_{2} \mathrm{Pn}_{2} \mathrm{O}>\mathrm{Na}_{2} \mathrm{Ti}_{2} \mathrm{Pn}_{2} \mathrm{O}>\mathrm{BaTi}_{2} \mathrm{Pn}_{2} \mathrm{O}$, which is the same trend as that in interlayer distance, indicating these two parameters are closely related to each other. Second, given the same $A$, $T_{\text {DW }}$ decreases in the order of $P n=\mathrm{As}>\mathrm{Pn}=\mathrm{Sb}>\mathrm{Pn}=\mathrm{Bi}$. Before the discovery of the superconducting compound $\mathrm{BaTi}_{2} \mathrm{Sb}_{2} \mathrm{O}$, only five compounds, $\mathrm{Na}_{2} \mathrm{Ti}_{2} \mathrm{As}_{2} \mathrm{O}, \mathrm{Na}_{2} \mathrm{Ti}_{2} \mathrm{Sb}_{2} \mathrm{O},(\mathrm{SrF})_{2} \mathrm{Ti}_{2} \mathrm{As}_{2} \mathrm{O},\left(\mathrm{SrF}_{2} \mathrm{Ti}_{2} \mathrm{Sb}_{2} \mathrm{O}\right.$, and $\mathrm{BaTi}_{2} \mathrm{As}_{2} \mathrm{O}$, have been known among titanium pnictide oxides. However, these five compounds are enough to find the trends mentioned above. We could expect that $A=\mathrm{Ba}$ and $P n=\mathrm{Sb}, \mathrm{BaTi}_{2} \mathrm{Sb}_{2} \mathrm{O}$, should have lower $T_{\mathrm{DW}}$ than the known titanium pnictide oxides, which may lead to superconductivity. Hence, we synthesized a new titanium pnictide oxides $\mathrm{BaTi}_{2} \mathrm{Sb}_{2} \mathrm{O}$ and found a $\mathrm{DW}$ transition at around $50 \mathrm{~K}$ and a superconducting transition at $1.2 \mathrm{~K}$. Moreover, for further suppression of DW instability, we synthesized $P n=\mathrm{Bi}$ compounds $\mathrm{BaTi}_{2} \mathrm{Bi}_{2} \mathrm{O}$ and $(\mathrm{SrF})_{2} \mathrm{Ti}_{2} \mathrm{Bi}_{2} \mathrm{O}$, which are the first examples of $P n=\mathrm{Bi}$ in the titanium pnictide oxides family. Though DW instability disappeared in both compounds, only $\mathrm{BaTi}_{2} \mathrm{Bi}_{2} \mathrm{O}$ shows superconductivity at $4.6 \mathrm{~K}$.

\section{Superconductivity in $\mathrm{BaTi}_{2} P n_{2} \mathrm{O}(P n=\mathrm{Sb}, \mathrm{Bi})$}

\subsection{Synthesis and Crystal Structure}

Polycrystalline samples of $\mathrm{BaTi}_{2} \mathrm{Sb}_{2} \mathrm{O}$ and $\mathrm{BaTi}_{2} \mathrm{Bi}_{2} \mathrm{O}$ were synthesized by the conventional solid-state reaction $[15,16]$. Stoichiometric amounts of $\mathrm{BaO}, \mathrm{Ti}$, and $\mathrm{Sb} / \mathrm{Bi}$ were mixed and pelletized. The pellet was wrapped with Ta foil and sealed in a quartz tube. The reaction temperature is $1000{ }^{\circ} \mathrm{C}$ for $\mathrm{BaTi}_{2} \mathrm{Sb}_{2} \mathrm{O}$, and $850{ }^{\circ} \mathrm{C}$ for $\mathrm{BaTi}_{2} \mathrm{Bi}_{2} \mathrm{O}$. Doan et al. also synthesized $\mathrm{BaTi}_{2} \mathrm{Sb}_{2} \mathrm{O}$ independently, where the precursors are sealed in $\mathrm{Nb}$ tubes under Ar gas and the reaction temperature is $900{ }^{\circ} \mathrm{C}$ [33]. The stability against ambient condition is lost when replacing $\mathrm{As}$ with $\mathrm{Sb}$ : $\mathrm{BaTi}_{2} \mathrm{Sb}_{2} \mathrm{O}$ is air- and moisture-sensitive while $\mathrm{BaTi}_{2} \mathrm{As}_{2} \mathrm{O}$ is not. Further replacement of $\mathrm{Sb}$ by Bi leads to increased sensitivity against air and moisture. The trend probably depends on the stability of $\mathrm{Pn}^{3-}$ ion against the oxidation. $\mathrm{BaTi}_{2} \mathrm{Bi}_{2} \mathrm{O}$ is indeed readily decomposed by exposure to the air or solvent, and Bi-based phases, such as $\mathrm{BaBi}_{3}$ and $\mathrm{Bi}$, are formed, where the $\mathrm{Bi}$ anion is oxidized from -3 to -0.66 and 0 , respectively.

Crystal structure of $\mathrm{BaTi}_{2} \mathrm{Sb}_{2} \mathrm{O}$ determined by XRD and neutron diffraction data is the same as that of $\mathrm{BaTi}_{2} \mathrm{As}_{2} \mathrm{O}$. The lattice constants are $a=4.11039(2) \AA, c=8.08640(4) \AA$ determined by synchrotron XRD data, and $a=4.1055(2) \AA, c=8.0712(4) \AA$ determined by neutron diffraction data. $\mathrm{BaTi}_{2} \mathrm{Bi}_{2} \mathrm{O}$ has also the same structure with lattice constants of $a=4.12316(4) \AA, c=8.3447(1) \AA$ which is determined by synchrotron XRD [15]. Compared with $\mathrm{BaTi}_{2} \mathrm{As}_{2} \mathrm{O}(a=4.046 \AA, c=7.272 \AA)$, replacement of As with $\mathrm{Sb} / \mathrm{Bi}$ leads to a distinct increase in the $c$-axis, whereas the increase in $a$-axis is small, as observed in other titanium pnictide oxides (see Table 1). Though the crystal structure of $\mathrm{BaTi}_{2} \mathrm{Pn}_{2} \mathrm{O}$ are similar to that of iron pnictides $\mathrm{BaFe}_{2} \mathrm{Pn}_{2}$ ( $\mathrm{ThCr}_{2} \mathrm{Si}_{2}$-type structure), such a trend is not observed in $\mathrm{BaFe}_{2} P n_{2}$ [34]. Both the structure of $\mathrm{BaTi}_{2} \mathrm{Pn}_{2} \mathrm{O}$ and $\mathrm{BaFe}_{2} \mathrm{Pn}_{2}$ can be regarded as an alternate stacking of $\mathrm{Ti}_{2} \mathrm{O}$ or $\mathrm{Fe}$ square lattice and $\mathrm{BaPn} n_{2}$ layer with $\mathrm{CsCl}$-type structural arrangement (see Figure 1). As the structural 
difference between these compounds is the square lattice, the trend of the lattice constant is probably due to the rigid nature of the $\mathrm{Ti}_{2} \mathrm{O}$ square lattice.

It is well known that the formation of the interlayer $\mathrm{X}-\mathrm{X}$ bond (the so-called lattice collapse) is often found in the $A B_{2} X_{2}$ compounds with the $\mathrm{ThCr}_{2} \mathrm{Si}_{2}$-type structure. As Hoffmann and Zheng pointed out, the formation of $\mathrm{X}-\mathrm{X}$ bond is promoted when $B$ is on the right-hand side of the periodic table and $X$ is on the higher period of the periodic table [35]. In accordance with the trend in $A B_{2} X_{2}$ compounds, the replacement of $\mathrm{As}$ by $\mathrm{Sb}$ or $\mathrm{Bi}$ in $\mathrm{BaTi}_{2} \mathrm{Pn}_{2} \mathrm{O}$ may allow the formation of an interlayer $P n-P n$ bond. However, the interatomic distance of $P n-P n$ in $\mathrm{BaTi}_{2} P n_{2} \mathrm{O}$ is $3.725 \AA$ for $P n=\mathrm{As}, 4.079 \AA$ for $P n=\mathrm{Sb}$, and $4.137 \AA$ for $P n=\mathrm{Bi}$, respectively, indicating the absence of the $P n-P n$ bond in all of the $\mathrm{BaTi}_{2} \mathrm{Pn}_{2} \mathrm{O}$. As the formation of the $\mathrm{X}-\mathrm{X}$ bond is often induced in $A B_{2} \mathrm{X}_{2}$ compounds by applying physical pressure or chemical pressure, the lattice collapse transition might be induced when sufficient pressure is applied.

\subsection{Superconductivity in $\mathrm{BaTi}_{2} \mathrm{Pn}_{2} \mathrm{O}$ and Its Superconducting Properties}

$\mathrm{BaTi}_{2} \mathrm{Sb}_{2} \mathrm{O}$ shows an anomaly in magnetic susceptibility, electrical resistivity, and lattice constants at around $50 \mathrm{~K}$ in analogy with other titanium pnictide oxides. The resistivity shows a metal-to-metal transition at around $50 \mathrm{~K}$ as observed in $\mathrm{BaTi}_{2} \mathrm{As}_{2} \mathrm{O}$ (Figure $6 \mathrm{~b}$ ). With decreasing temperature, the magnetic susceptibility slightly increases and a small drop is observed at the same temperature (Figure 6c). An anomaly in the lattice constants $a$ and $c$ is highly similar to that observed in $\mathrm{Na}_{2} \mathrm{Ti}_{2} \mathrm{Sb}_{2} \mathrm{O}$, as shown in Figure 6a. The transition temperature is much lower than that of $\mathrm{BaTi}_{2} \mathrm{As}_{2} \mathrm{O}\left(T_{\mathrm{DW}}=200 \mathrm{~K}\right)$, as expected from the trends mentioned above.
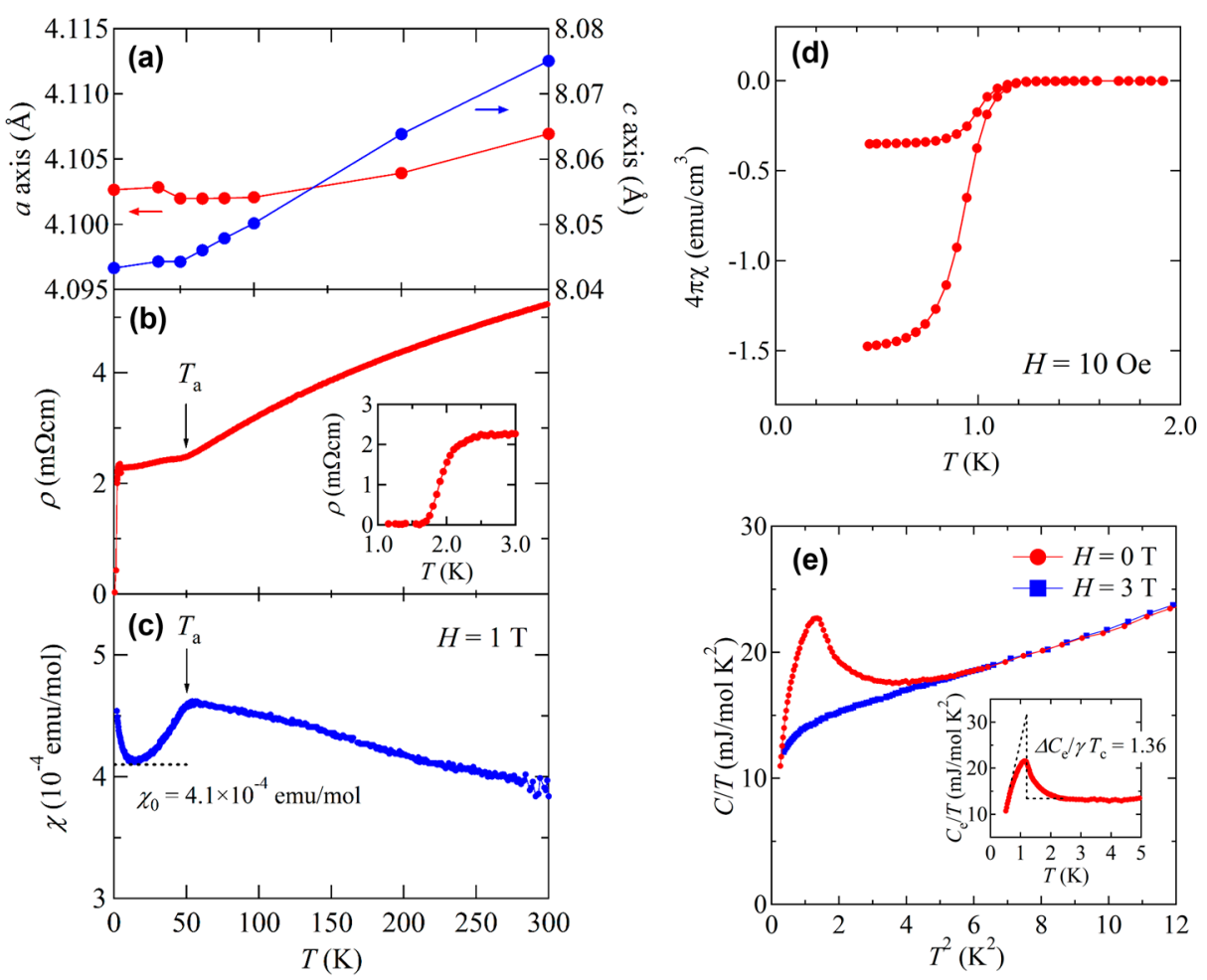

Figure 6. Temperature dependence of (a) lattice constants $a$ and $c$; (b) electrical resistivity; (c) magnetic susceptibility at $1 \mathrm{~T}$ for $\mathrm{BaTi}_{2} \mathrm{Sb}_{2} \mathrm{O}$; (d) low-temperature magnetic susceptibility at 10 Oe for $\mathrm{BaTi}_{2} \mathrm{Sb}_{2} \mathrm{O}$; (e) low-temperature specific heat for $\mathrm{BaTi}_{2} \mathrm{Sb}_{2} \mathrm{O}$.

$\mathrm{BaTi}_{2} \mathrm{Sb}_{2} \mathrm{O}$ also shows superconducting transition at $1.2 \mathrm{~K}$ coexisting with the DW instability. As shown in Figure 6d, the magnetization shows a sharp drop at $1.2 \mathrm{~K}$ and shielding volume fraction is as large as $100 \%$ at $0.5 \mathrm{~K}$. Electrical resistivity exhibits a sharp drop to zero at around $2 \mathrm{~K}$ as 
shown in the inset of Figure $6 \mathrm{~b}$. Specific heat of $\mathrm{BaTi}_{2} \mathrm{Sb}_{2} \mathrm{O}$ shows a distinct peak at around $1.2 \mathrm{~K}$, which is firm evidence of bulk superconductivity in $\mathrm{BaTi}_{2} \mathrm{Sb}_{2} \mathrm{O}$ (Figure 6e). Note that the origin of the small fraction of superconductivity at around $2 \mathrm{~K}$ is not clear, but might be due to the sample quality. The Sommerfeld coefficient $\gamma$ and the Debye temperature $\theta_{D}$ estimated from the specific data are $13.5 \mathrm{~mJ} \cdot \mathrm{mol}^{-1} \cdot \mathrm{K}^{-2}$ and $239 \mathrm{~K}$, respectively, which are similar to those of the As analogue $\left(\gamma=15.3 \mathrm{~mJ} \cdot \mathrm{mol}^{-1} \cdot \mathrm{K}^{-2}\right.$ and $\left.\theta_{D}=223 \mathrm{~K}\right)$. The value of $\Delta C\left(T_{\mathrm{c}}\right) / \gamma T_{\mathrm{c}}$ estimated from the specific heat jump is 1.36, which is almost consistent with the Bardeen-Cooper-Schrieffer (BCS) weak coupling limit of 1.43. Gooch et al. improved sample quality and reported the specific heat data where a sharper change at $T_{\mathrm{c}}$ was observed. The obtained $\gamma, \theta_{D}$, and $\Delta C\left(T_{\mathrm{c}}\right) / \gamma T_{\mathrm{c}}$ are $10.9 \mathrm{~mJ} \cdot \mathrm{mol}^{-1} \cdot \mathrm{K}^{-2}, 230 \mathrm{~K}$, and 0.9 , respectively, which are smaller than those of our previous study $[15,36]$. The temperature dependence of electronic specific heat $C_{\mathrm{el}} / \gamma T$ can be fitted by the so-called $\alpha$ model with $\alpha=1.4$, rather than BCS theory, suggesting a single-gap s-wave superconductivity with a gap of $2 \Delta=0.3 \mathrm{meV}$.

The $s$-wave nature of the superconductivity is also suggested from the ${ }^{121} \mathrm{Sb}$-nuclear quadrupole resonance (NQR) measurements and the muon spin relaxation/rotation $(\mu \mathrm{SR})$ measurements: the temperature dependence of $1 / T_{1}$ in the ${ }^{121} \mathrm{Sb}-\mathrm{NQR}$ measurements shows a tiny coherence peak at around $1 \mathrm{~K}$ (Figure 7a), and temperature dependence of superconducting relaxation rate $\sigma_{\mathrm{SC}}$ obtained from $\mu \mathrm{SR}$ measurements can be fitted well by the BCS s-wave model in the weak coupling limit $[37,38]$. Note that the ${ }^{121} \mathrm{Sb}-\mathrm{NQR}$ measurements also revealed that the microscopic coexistence of superconductivity and DW instability in $\mathrm{BaTi}_{2} \mathrm{Sb}_{2} \mathrm{O}$. Though a magnetic fluctuation has been observed at around $T_{\mathrm{DW}}$ in $1 / T_{1} T$, the origin of the fluctuation has not clarified yet (see Figure $7 \mathrm{~b}$ ).

(a)

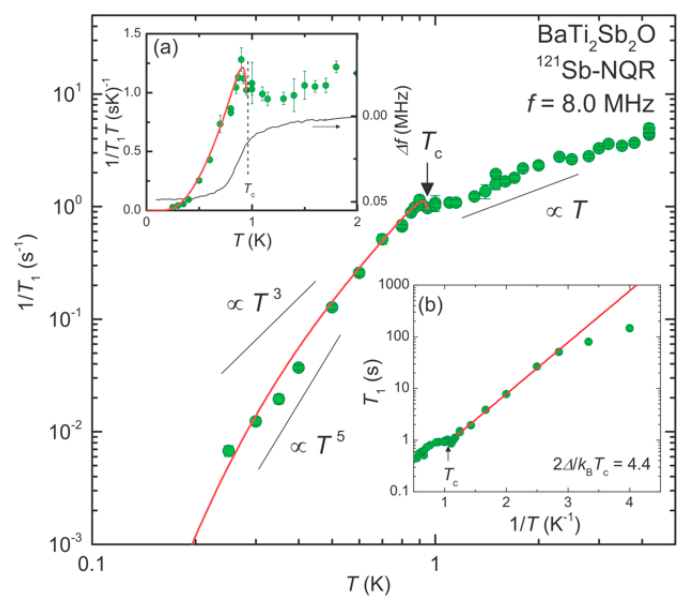

(b)

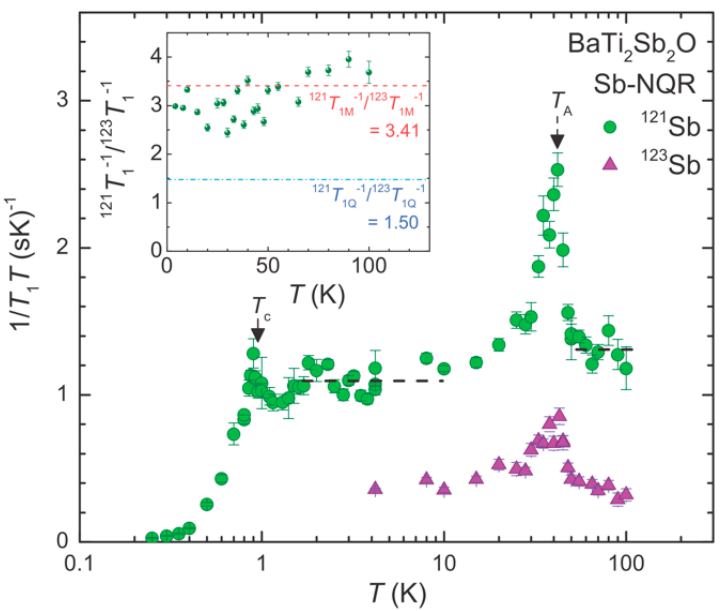

Figure 7. (a) Temperature dependence of $1 / T_{1}$ measured at $8.0 \mathrm{MHz}$; (b) Temperature dependence of $1 / T_{1} T$ measured with ${ }^{121 / 123} \mathrm{Sb}-\mathrm{NQR}$. The inset shows temperature dependence of the ${ }^{121 / 123} \mathrm{Sb}$ isotopic ratio ${ }^{121} T_{1}{ }^{-1} /{ }^{123} T_{1}{ }^{-1}$. Reprinted with permission from Kitagawa et al., Phys. Rev. B; published by APS, 2013.

$\mathrm{BaTi}_{2} \mathrm{Bi}_{2} \mathrm{O}$ shows paramagnetic behavior in magnetic susceptibility and metallic temperature dependence in electrical resistivity, like $\mathrm{BaTi}_{2} \mathrm{As}_{2} \mathrm{O}$ and $\mathrm{BaTi}_{2} \mathrm{Sb}_{2} \mathrm{O}$. However, no anomaly is observed in both data (Figure 8a), indicating the DW transition is further suppressed and disappears by replacing $\mathrm{Sb}$ with $\mathrm{Bi}$, as expected from the trend discussed above. Reflecting the further suppression of DW instability, $\mathrm{BaTi}_{2} \mathrm{Bi}_{2} \mathrm{O}$ has an enhanced $T_{\mathrm{c}}$ of $4.6 \mathrm{~K}$ as seen in the magnetic susceptibility and electrical resistivity. Due to the extremely high air- and moisture-sensitivity, the specific heat of $\mathrm{BaTi}_{2} \mathrm{Bi}_{2} \mathrm{O}$ has not been measured. However, shielding volume fraction exceeds $60 \%$ at $1.85 \mathrm{~K}$ (Figure $8 \mathrm{~b}$ ), providing a firm evidence of bulk superconductivity in $\mathrm{BaTi}_{2} \mathrm{Bi}_{2} \mathrm{O}$ [16]. 


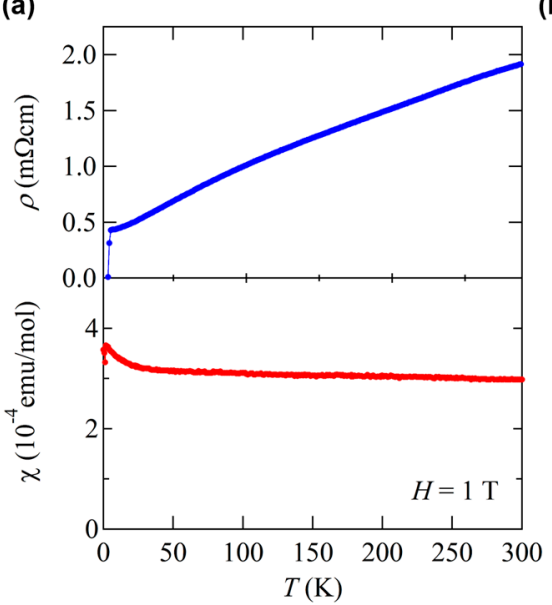

(b)

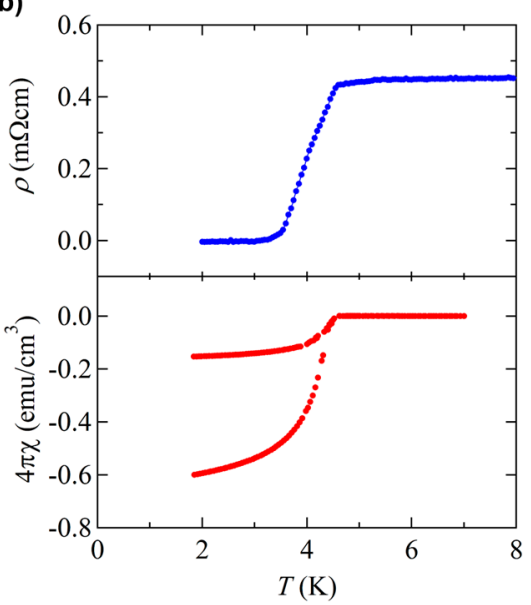

Figure 8. (a) Temperature dependence of electrical resistivity and magnetic susceptibility under $1 \mathrm{~T}$ for $\mathrm{BaTi}_{2} \mathrm{Bi}_{2} \mathrm{O}$. No DW transition is observed. (b) Low-temperature resistivity and magnetic susceptibility at 5 Oe for $\mathrm{BaTi}_{2} \mathrm{Bi}_{2} \mathrm{O}$.

The magnetic field dependence of $T_{c}$ for $\mathrm{BaTi}_{2} \mathrm{Sb}_{2} \mathrm{O}$ and $\mathrm{BaTi}_{2} \mathrm{Bi}_{2} \mathrm{O}$ are shown in Figure $9 \mathrm{a}, \mathrm{b}$ where the $T_{\mathrm{C}}$ is determined from the midpoint of the resistive transition. As shown in Figure $9 \mathrm{c}$, the temperature dependence of the upper critical field $H_{\mathrm{c} 2}$ increases almost linearly with decreasing temperature down to the lowest temperature measured. $H_{\mathrm{c} 2}$ at $0 \mathrm{~K}, H_{\mathrm{c} 2}(0)$, are $1.32 \mathrm{~T}$ for $\mathrm{BaTi}_{2} \mathrm{Sb}_{2} \mathrm{O}$ and $1.70 \mathrm{~T}$ for $\mathrm{BaTi}_{2} \mathrm{Bi}_{2} \mathrm{O}$ (Figure 9c), which is estimated from the linear extrapolation of the data. From the value of $H_{\mathrm{c} 2}(0)$, the coherence length $\xi_{0}$ is estimated to be $158 \AA$ and $139 \AA$ for $\mathrm{BaTi}_{2} \mathrm{Sb}_{2} \mathrm{O}$ and $\mathrm{BaTi}_{2} \mathrm{Bi}_{2} \mathrm{O}$, respectively [39]. The superconducting parameters of $\mathrm{BaTi}_{2} \mathrm{Sb}_{2} \mathrm{O}$ determined by specific heat data is reported by Gooch et al. where $H_{\mathrm{c} 2}(0)$ and $\xi_{0}$ is estimated to be $0.08 \mathrm{~T}$ and $640 \AA$ [36]. Though the origin of the discrepancy in the parameter of $\mathrm{BaTi}_{2} \mathrm{Sb}_{2} \mathrm{O}$ between [34] and [37] is not clear yet, it might come from the sample quality or the filamentary superconductivity which enhances the resistive $H_{\mathrm{c} 2}$ in $\mathrm{BaTi}_{2} \mathrm{Sb}_{2} \mathrm{O}$. To clarify the origin, the measurements on single crystalline sample should be performed. The lower critical field $H_{\mathrm{c} 1}$ for $\mathrm{BaTi}_{2} \mathrm{Bi}_{2} \mathrm{O}$ is estimated from the magnetic field dependence of zero-field cooled magnetization at various temperatures (Figure 10a). The $H_{\mathrm{c} 1}$ as a function of $\left(T / T_{\mathrm{c}}\right)^{2}$ is shown in Figure 10b. The $H_{\mathrm{c} 1}(0)$ is estimated to be 60 Oe from the linear extrapolation of the data (Figure 10b), which corresponds to the penetration depth of $2900 \AA$. Note that, $H_{\mathrm{c} 1}(0)$ for $\mathrm{BaTi}_{2} \mathrm{Sb}_{2} \mathrm{O}$ has not been determined due to its low $T_{\mathrm{c}}$.

(a)

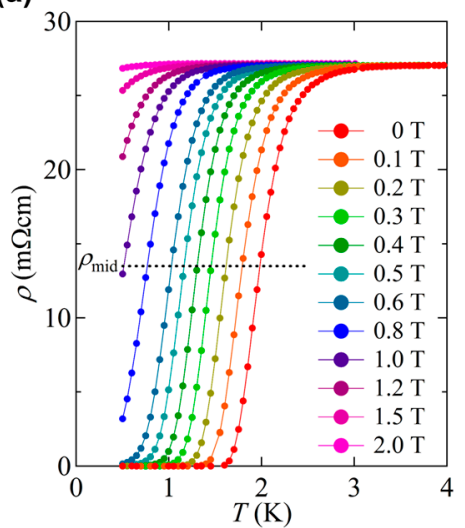

(b)

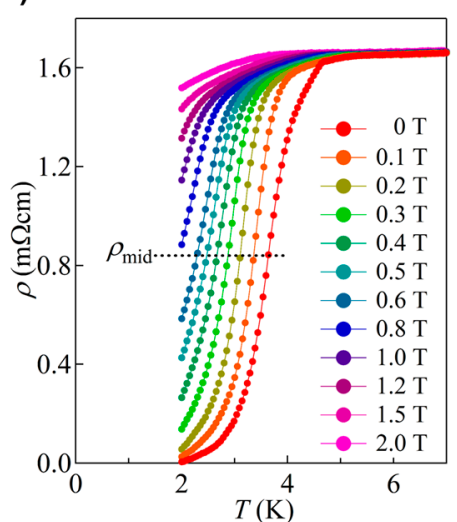

(c)

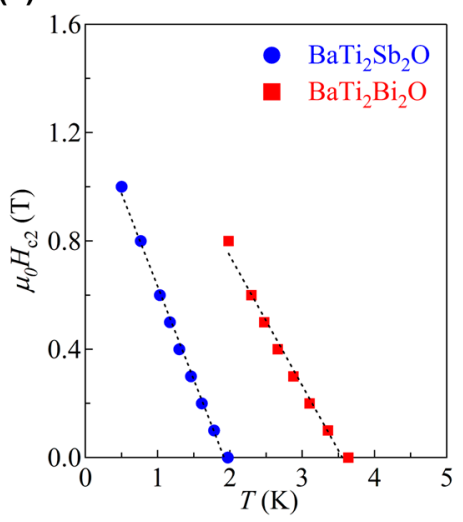

Figure 9. Temperature dependence of the electrical resistivity for (a) $\mathrm{BaTi}_{2} \mathrm{Sb}_{2} \mathrm{O}$ and (b) $\mathrm{BaTi}_{2} \mathrm{Bi}_{2} \mathrm{O}$ under various magnetic fields; (c) temperature dependence of $H_{\mathrm{c} 2}$ for $\mathrm{BaTi}_{2} \mathrm{Sb}_{2} \mathrm{O}$ and $\mathrm{BaTi}_{2} \mathrm{Bi}_{2} \mathrm{O}$. 
Though the specific heat data of $\mathrm{BaTi}_{2} \mathrm{Bi}_{2} \mathrm{O}$ is not available due to the extremely air- and moisture-sensitivity, $D\left(E_{\mathrm{F}}\right)$ of $\mathrm{BaTi}_{2} \mathrm{Bi}_{2} \mathrm{O}$ can be estimated from the obtained superconducting parameters, the equation for weak-coupling limit, $\left[\mu_{0} H_{\mathrm{c}}(0)\right]^{2} / 8 \pi=D\left(E_{\mathrm{F}}\right) \Delta(0)^{2} / 2$, and $\Delta(0)=1.764 k_{\mathrm{B}} T_{\mathrm{C}}$, where $\Delta(0)$ is superconducting gap. The $D\left(E_{\mathrm{F}}\right)$ of $\mathrm{BaTi}_{2} \mathrm{Bi}_{2} \mathrm{O}$ is estimated to be 4.79 states $/ \mathrm{eV} / \mathrm{f}$.u. For $\mathrm{BaTi}_{2} \mathrm{Sb}_{2} \mathrm{O}$, using $\gamma$ obtained from specific heat data, $D\left(E_{\mathrm{F}}\right)$ is estimated to be 5.7 states $/ \mathrm{eV} / \mathrm{f}$.u. from the equation, $\gamma=\pi^{2} D\left(E_{\mathrm{F}}\right) k_{\mathrm{B}}{ }^{2} / 3$. Though $T_{\mathrm{c}}$ of $\mathrm{BaTi}_{2} \mathrm{Bi}_{2} \mathrm{O}$ is much higher than that of $\mathrm{BaTi}_{2} \mathrm{Sb}_{2} \mathrm{O}$, the experimentally estimated $D\left(E_{\mathrm{F}}\right)$ of $\mathrm{BaTi}_{2} \mathrm{Bi}_{2} \mathrm{O}$ is smaller than that of $\mathrm{BaTi}_{2} \mathrm{Sb}_{2} \mathrm{O}$. Since $\mathrm{BaTi}_{2} \mathrm{Bi}_{2} \mathrm{O}$ is isostructural with $\mathrm{BaTi}_{2} \mathrm{Sb}_{2} \mathrm{O}$, the slightly smaller Debye temperature $\theta_{D}$ is expected, reflecting the replacement of $\mathrm{Sb}$ by the heavier Bi. In the BCS weak-coupling limit, the decrease in both $D\left(E_{\mathrm{F}}\right)$ and $\theta_{D}$ leads the decreased $T_{\mathrm{c}}$. Thus, the enhanced $T_{\mathrm{c}}$ in $\mathrm{BaTi}_{2} \mathrm{Bi}_{2} \mathrm{O}$ cannot be explained by the $\mathrm{BCS}$ weak-coupling limit.

(a)

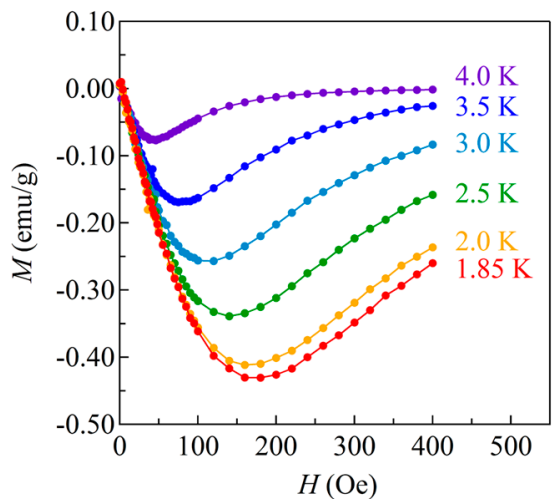

(b)

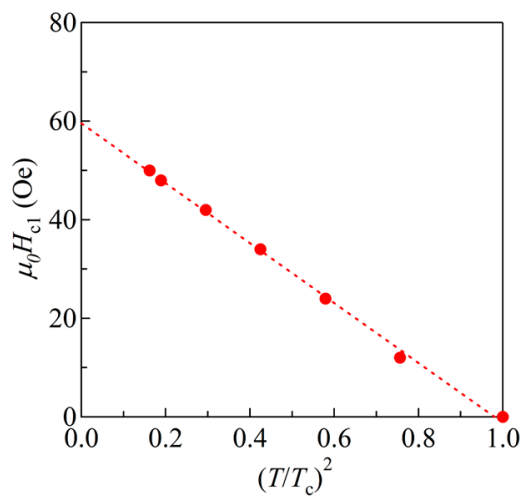

Figure 10. (a) Magnetic field dependence of magnetization for $\mathrm{BaTi}_{2} \mathrm{Bi}_{2} \mathrm{O}$ at various temperature; (b) the temperature dependence of the lower critical field $H_{\mathrm{c} 1}$ for $\mathrm{BaTi}_{2} \mathrm{Bi}_{2} \mathrm{O}$.

\subsection{Electronic Structure of $\mathrm{BaTi}_{2} \mathrm{Pn}_{2} \mathrm{O}$}

The electronic structure is a key toward understanding of superconductivity and DW instability in $\mathrm{BaTi}_{2} \mathrm{Pn}_{2} \mathrm{O}$. Several theoretical studies have addressed the electronic structure of $\mathrm{BaTi}_{2} \mathrm{Sb}_{2} \mathrm{O}$. The electronic structure for $\mathrm{BaTi}_{2} \mathrm{Sb}_{2} \mathrm{O}$ based on the first principles calculations was first reported by Singh [40]. The calculation revealed three $d$ orbitals, $d_{x y}, d_{x^{2}-y^{2}}$, and $d_{z^{2}}$, contribute significantly at the Fermi level $\left(E_{\mathrm{F}}\right)$, indicating the multiband nature of $\mathrm{BaTi}_{2} \mathrm{Sb}_{2} \mathrm{O}$. The $\mathrm{O} 2 p$ and $\mathrm{Sb} 5 p$ bands are nominally full, while $\mathrm{Sb} 5 p$ are hybridized with $\mathrm{Ti} 3 d$, and there are no Ba-derived occupied valence bands. The results indicate the formal valence is $\mathrm{Ba}^{2+} \mathrm{Ti}^{3+} \mathrm{Sb}^{3-} \mathrm{O}^{2-}$ as expected. The calculated Fermi surface (FS) is shown in Figure 11 where three sheets of FS, namely two electron sheets and one hole sheet, have been found. The square cylinder around the $M$ and $A$ points is an electron sheet with a two-dimensional character, which is the mixture of three $d$ orbitals, $d_{x y}, d_{x^{2}-y^{2}}$, and $d_{z^{2}}$. Another electron sheet is a three-dimensional complex-shaped section around the $\Gamma$ and $Z$ points, which has $d_{z^{2}}$ character. The three-dimensional hole sheet located around the $R$ point is derived from the mixture of three $d$ orbitals, where the sheet compensates other two electron sheets reflecting that an even electron count in $\mathrm{BaTi}_{2} \mathrm{Sb}_{2} \mathrm{O}$. Consistent results for the $\mathrm{FS}$ of $\mathrm{BaTi}_{2} \mathrm{Sb}_{2} \mathrm{O}$ were also obtained in other theoretical studies [41-43]. The electronic structure for $\mathrm{BaTi}_{2} \mathrm{Bi}_{2} \mathrm{O}$ have been obtained by Suetin et al., [44]. As in the case with $\mathrm{BaTi}_{2} \mathrm{Sb}_{2} \mathrm{O}$, at $E_{\mathrm{F}}$, three $d$ orbitals contribute significantly and the topology of FS is highly similar to that in $\mathrm{BaTi}_{2} \mathrm{Sb}_{2} \mathrm{O}$. These predicted $\mathrm{FS}$ of $\mathrm{BaTi}_{2} \mathrm{Pn}_{2} \mathrm{O}$ is highly similar to that theoretically predicted in $\mathrm{Na}_{2} \mathrm{Ti}_{2} \mathrm{Pn}_{2} \mathrm{O}[25,32,45]$. Experimentally, Song et al. recently performed angle-resolved photoemission spectroscopy (ARPES) studies on $\mathrm{Ba}_{0.95} \mathrm{Na}_{0.05} \mathrm{Ti}_{2} \mathrm{Sb}_{2} \mathrm{O}$ single crystals and found the multiband electronic structure having electron and hole pockets, consistent with the theoretical studies [46]. 

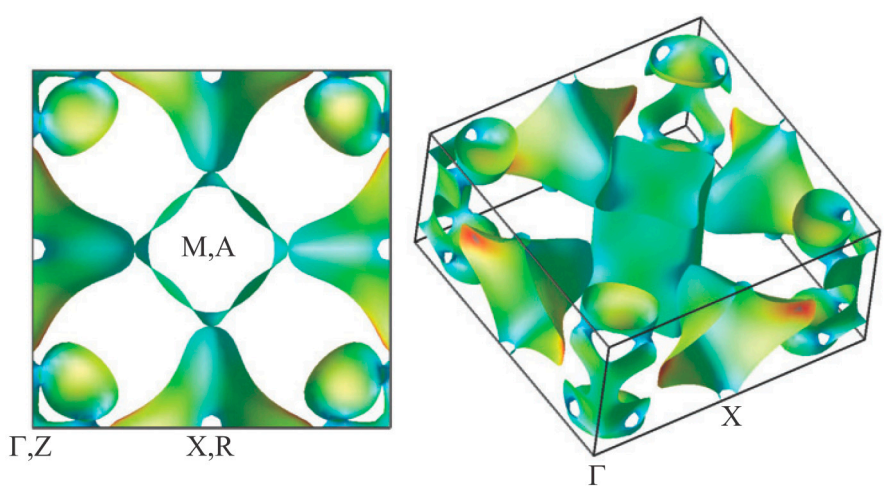

Figure 11. Calculated Fermi surfaces of $\mathrm{BaTi}_{2} \mathrm{Sb}_{2} \mathrm{O}$, where spin-orbit interaction are included. Square cylindrical section around $M, A$, and complex-shaped sections around $\Gamma, Z$ are electron sections. The other section around $R$ is a hole section. Reprinted with permission from Singh, New. J. Phys.; published by IOP, 2012 [40].

The $D\left(E_{\mathrm{F}}\right)$ for $\mathrm{BaTi}_{2} \mathrm{Sb}_{2} \mathrm{O}$ is theoretically estimated to be 4.26 states/eV/f.u. by Singh, 3.88 states/eV/f.u. by Subedi, 3.599 states/eV/f.u. by Suetin et al. [32,41,47] where the calculations are based on the structure determined at room temperature (see Figure 1) and the structural distortion due to DW instability is not considered because the low temperature structure is not clarified yet. Subedi pointed out the possible lattice instability toward CDW with a $\sqrt{ } 2 \times \sqrt{ } 2 \times 1$ superlattice based on the calculation of phonon dispersions. When the suggested lattice distortion is taken into account, the $D\left(E_{\mathrm{F}}\right)$ is found to be 2.83 state/eV/f.u., which suggests $\sim 30 \%$ decrease through the DW transition. Note that the decrease in $D\left(E_{\mathrm{F}}\right)$ below $T_{\mathrm{DW}}$ is experimentally found to be $9 \%$ by NQR measurements (see Figure $7 \mathrm{~b}$ ) [38]. These $D\left(E_{\mathrm{F}}\right)$ estimated from the theoretical studies are somewhat smaller than that estimated from the experimentally obtained $\gamma\left(D\left(E_{\mathrm{F}}\right)=5.7\right.$ states/eV/f.u. $)$, implying that the $\gamma$ is enhanced by electron-phonon coupling in $\mathrm{BaTi}_{2} \mathrm{Sb}_{2} \mathrm{O}$ [15]. For $\mathrm{BaTi}_{2} \mathrm{Bi}_{2} \mathrm{O}$, the $D\left(E_{\mathrm{F}}\right)$ of 3.42 states $/ \mathrm{eV} /$ f.u. has been obtained by Suetin et al., which is also smaller than experimental $D\left(E_{\mathrm{F}}\right)$ of 4.79 states/eV/f.u. [16,44].

The $T_{\mathrm{c}}$ of $\mathrm{BaTi}_{2} \mathrm{Sb}_{2} \mathrm{O}$ has been estimated by Subedi and Nakano et al. using the Allen-Dynes formula, and found to be $2.7 \mathrm{~K}$ and $2.30 \mathrm{~K}$, respectively [43,47]. The estimated $T_{\mathrm{c}}$ is almost consistent with the experimental value $\left(T_{c}=1.2 \mathrm{~K}\right)$, suggesting $\mathrm{BaTi}_{2} \mathrm{Sb}_{2} \mathrm{O}$ is a conventional BCS-type superconductor. Nakano et al. also estimated the $T_{\mathrm{c}}$ of $\mathrm{BaTi}_{2} \mathrm{Bi}_{2} \mathrm{O}$ to be $2.45 \mathrm{~K}$ using the same method, which is relatively smaller than the experimental value $\left(T_{\mathrm{c}}=4.6 \mathrm{~K}\right)$. The theoretically estimated $T_{\mathrm{c}}$-values for $\mathrm{BaTi}_{2} \mathrm{Sb}_{2} \mathrm{O}$ and $\mathrm{BaTi}_{2} \mathrm{Bi}_{2} \mathrm{O}$ are similar to each other, where the experimental results, namely the enhancement of $T_{\mathrm{c}}$ by replacing $\mathrm{Sb}$ with $\mathrm{Bi}$, could not be explained.

\subsection{Isovalent Substitution Effect on $\mathrm{BaTi}_{2} \mathrm{Pn}_{2} \mathrm{O}$}

As discussed in above, the enhanced $T_{c}$ of $\mathrm{BaTi}_{2} \mathrm{Bi}_{2} \mathrm{O}$ cannot be explained in the $\mathrm{BCS}$ weakcoupling limit. To find a clue, the effect of isovalent substitution, solid solutions of $\mathrm{BaTi}_{2}\left(\mathrm{As}_{1-x} \mathrm{Sb}_{x}\right)_{2} \mathrm{O}$ and $\mathrm{BaTi}_{2}\left(\mathrm{Sb}_{1-y} \mathrm{Bi}_{y}\right)_{2} \mathrm{O}$, have been investigated [18]. The lattice constants and electronic phase diagram of the isovalent solid solutions are shown in Figure 12a. The lattice constants of these solid solutions follow Vegard's law, indicating the solid solutions are formed and no structural transition is induced by isovalent substitution. With increasing $x, T_{\mathrm{DW}}$ decreases and superconducting phase appears at around $x=0.9\left(T_{\mathrm{c}}=0.5 \mathrm{~K}\right)$, where $T_{\mathrm{DW}}$ and $T_{\mathrm{c}}$ are determined from the resistivity data. For the solid solution of $\mathrm{BaTi}_{2}\left(\mathrm{Sb}_{1-y} \mathrm{Bi}_{y}\right)_{2} \mathrm{O}, T_{\mathrm{c}}$ is determined from the magnetization data. With increasing $y$, $T_{\mathrm{c}}$ initially increases up to $3.5 \mathrm{~K}$ at $y=0.2$, and then monotonically decreases down to $2.6 \mathrm{~K}$ at $y=0.3$. For $y=0.4$ and 0.5 , bulk superconductivity is not observed down to $1.85 \mathrm{~K}$, which is the instrumental limit. At $y=0.6$, bulk superconductivity with $T_{\mathrm{c}}=4.0 \mathrm{~K}$ appears again and $T_{\mathrm{c}}$ increases with increasing $y$ up to $4.6 \mathrm{~K}$ at $y=1.0$. The isovalent substitution effect for $0 \leq y \leq 0.4$ has also been reported by 
Zhai et al., where the electronic phase diagram is almost the same as our results: $T_{\mathrm{c}}$ increases up to $3.7 \mathrm{~K}$ at $y=0.17$, then gradually decreases above $y=0.2$. Moreover, the $T_{\mathrm{DW}}$ decreases with increasing $y$, and the DW transition could not be observed above $y=0.17$ [48].

From the overall electronic phase diagram shown in Figure 12a, we can find two-dome structure in $T_{\mathrm{c}}$ : the first dome ranges in $0.9 \leq x \leq 1$ and $0 \leq y \leq 0.3$, and the second dome ranges $0.6 \leq y \leq 1$. The first superconducting phase seems to be induced by the suppression of DW phase, which is often seen in the CDW/SDW superconductors. However, the disappearance of superconductivity and a steep rise of $T_{\mathrm{c}}$ in the vicinity of the second superconducting phase implies the second superconducting phase may have a different mechanism behind superconductivity from the first superconducting phase. A two-dome structure in $T_{\mathrm{c}}$ has also seen in the iron pnictide superconductors such as $\operatorname{LaFeAs}\left(\mathrm{O}_{1-x} \mathrm{H}_{x}\right)$ [49-51]. In the phase diagram of $\operatorname{LaFeAs}\left(\mathrm{O}_{1-x} \mathrm{H}_{x}\right)(0 \leq x \leq 0.6)$, the first superconducting dome $(0.05 \leq x \leq 0.20)$ with a maximum $T_{\mathrm{c}}$ of $29 \mathrm{~K}$ and the second dome $(0.20 \leq x \leq 0.42)$ with a maximum $T_{\mathrm{c}}$ of $36 \mathrm{~K}$ appear with two antiferromagnetic phases $(x<0.05$ and $0.4<x)\left[49\right.$ ]. Though the two-dome structure in $\mathrm{LaFeAs}\left(\mathrm{O}_{1-x} \mathrm{H}_{x}\right)$ emerges by electron doping, in contrast to the two-dome structure in $\mathrm{BaTi}_{2} \mathrm{Pn}_{2} \mathrm{O}$ emerging by isovalent substitution, both $\mathrm{BaTi}_{2} \mathrm{Pn}_{2} \mathrm{O}$ and iron based superconductors have a multiband nature. Hence, $\mathrm{BaTi}_{2} \mathrm{Pn}_{2} \mathrm{O}$ might offer an opportunity to understand the nature of high $T_{\mathrm{c}}$ superconductivity in iron pnictides.

(a)

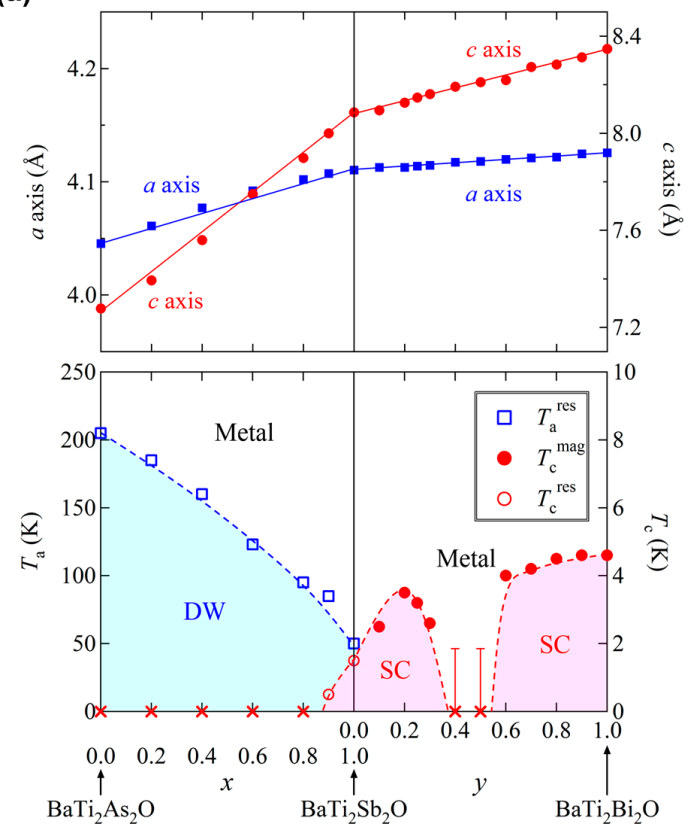

(b)

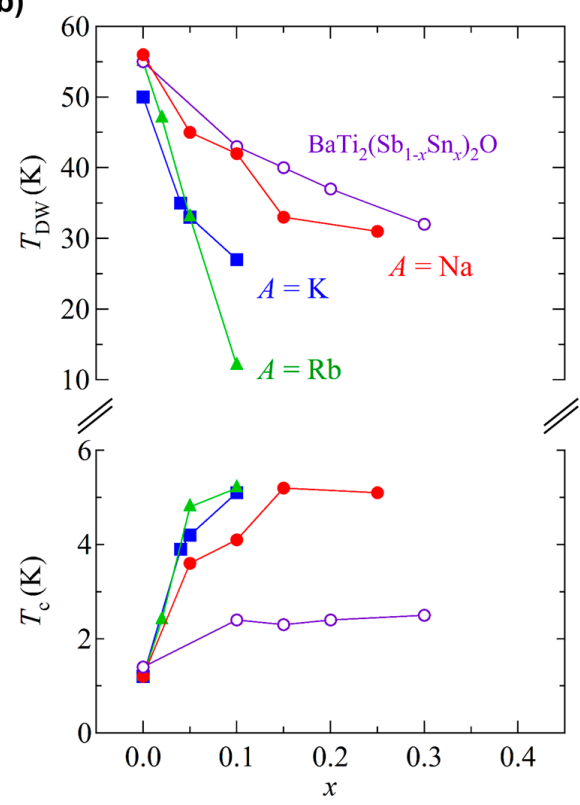

Figure 12. (a) Lattice constants and electronic phase diagram of isovalent solid solutions $\mathrm{BaTi}_{2}\left(\mathrm{Sb}_{1-x} \mathrm{Bi}\right)_{2} \mathrm{O}$; (b) $T_{\mathrm{DW}}$ and $T_{\mathrm{c}}$ for aliovalent substitution compounds $\left(\mathrm{Ba}_{1-x} A_{x}\right) \mathrm{Ti}_{2} \mathrm{Sb}_{2} \mathrm{O}$ and $\mathrm{BaTi}_{2}\left(\mathrm{Sb}_{1-x} \mathrm{Sn}_{x}\right)_{2} \mathrm{O}$ as a function of $x$.

\subsection{Aliovalent Substitution Effect on $\mathrm{BaTi}_{2} \mathrm{Pn}_{2} \mathrm{O}$}

In $\mathrm{BaTi}_{2} \mathrm{Sb}_{2} \mathrm{O}$, superconductivity emerges by the suppression of DW instability. However, DW instability is not fully suppressed and coexists with superconductivity, indicating that the further suppression of DW instability may enhance $T_{\mathrm{c}}$. Several aliovalent substitutions, $\left(\mathrm{Ba}_{1-x} A_{x}\right) \mathrm{Ti}_{2} \mathrm{Sb}_{2} \mathrm{O}$ $(A=$ alkali metal: $\mathrm{Na}, \mathrm{K}, \mathrm{Rb})$ and $\mathrm{BaTi}_{2}\left(\mathrm{Sb}_{1-x} \mathrm{Sn}_{x}\right)_{2} \mathrm{O}$, have been reported, where all of them are hole-doped systems. The lattice constant $a$ decreases with increasing $x$ for all dopants, reflecting the size reduction of titanium ions upon hole doping. However, $c$ of $\left(\mathrm{Ba}_{1-x} A_{x}\right) \mathrm{Ti}_{2} \mathrm{Sb}_{2} \mathrm{O}$ increases with increasing $x$, whereas that of $\mathrm{BaTi}_{2}\left(\mathrm{Sb}_{1-x} \mathrm{Sn}_{x}\right)_{2} \mathrm{O}$ decreases. The increase of $c$ for $\left(\mathrm{Ba}_{1-x} A_{x}\right) \mathrm{Ti}_{2} \mathrm{Sb}_{2} \mathrm{O}$ may 
come from the reduced Coulomb attraction between $\mathrm{Ba} / A$ and $\mathrm{Sb}$ due to the substitution of $\mathrm{Ba}$ for lower valence cation $A$.

On the basis of these substitution effects, $T_{\mathrm{DW}}$ and $T_{\mathrm{C}}$ as a function of $x$ is summarized in Figure 12b. The substitution effects are qualitatively the same: the DW phase is destabilized gradually and $T_{\mathrm{c}}$ is enhanced with increasing $x$. This indicates that the DW phase and superconducting phase compete with each other in $\mathrm{BaTi}_{2} \mathrm{Sb}_{2} \mathrm{O}$, and hole doping is generally effective for the suppression of DW instability and the enhancement of $T_{\mathrm{c}}$. In $\left(\mathrm{Ba}_{1-x} \mathrm{Na}_{x}\right) \mathrm{Ti}_{2} \mathrm{Sb}_{2} \mathrm{O}, T_{\mathrm{c}}$ increases up to $5.5 \mathrm{~K}$ at $x=0.15$ and show a plateau at higher $x$ value [33]. Likewise, the maximum $T_{\mathrm{c}}$ of $6.1 \mathrm{~K}$ and $5.4 \mathrm{~K}$ are attained at $x=0.12$ for $\left(\mathrm{Ba}_{1-x} \mathrm{~K}_{x}\right) \mathrm{Ti}_{2} \mathrm{Sb}_{2} \mathrm{O}$ [52] and $x=0.2$ for $\left(\mathrm{Ba}_{1-x} \mathrm{Rb}_{x}\right) \mathrm{Ti}_{2} \mathrm{Sb}_{2} \mathrm{O}$ [53], respectively. In contrast to $\left(\mathrm{Ba}_{1-x} A_{x}\right) \mathrm{Ti}_{2} \mathrm{Sb}_{2} \mathrm{O}, \mathrm{BaTi}_{2}\left(\mathrm{Sb}_{1-x} \mathrm{Sn}_{x}\right)_{2} \mathrm{O}$ provides a quantitatively different phase diagram: the maximum $T_{\mathrm{c}}$ of $2.5 \mathrm{~K}$ is attained at $x=0.3$, which is less than half of that for $\left(\mathrm{Ba}_{1-x} A_{x}\right) \mathrm{Ti}_{2} \mathrm{Sb}_{2} \mathrm{O}$ [54]. The quantitative difference between $\left(\mathrm{Ba}_{1-x} A_{x}\right) \mathrm{Ti}_{2} \mathrm{Sb}_{2} \mathrm{O}$ and $\mathrm{BaTi}_{2}\left(\mathrm{Sb}_{1-x} \mathrm{Sn}_{x}\right)_{2} \mathrm{O}$ is probably due to disorder effects. The $\mathrm{Sn}$ substitution induces much greater disorder effects on the superconductivity than alkali substitutions since $\mathrm{Sn}$ substitutes the superconducting $\mathrm{Ti}_{2} \mathrm{Sb}_{2} \mathrm{O}$ layer while alkali substitutes the Ba blocking layer. Note that the similar behavior of the suppression of DW instability and enhancement of $T_{c}$, has been observed in a high-pressure study on $\mathrm{BaTi}_{2} \mathrm{Sb}_{2} \mathrm{O}$ where the electrical resistivity is measured under a pressure up to $16.12 \mathrm{kbar}$. By applying pressure, the $T_{\mathrm{DW}}$ is monotonically suppressed down to $\sim 40 \mathrm{~K}$, whereas $T_{\mathrm{c}}$ increases up to $2.9 \mathrm{~K}$ [55].

The superconducting parameters for non-doped $\mathrm{BaTi}_{2} \mathrm{Sb}_{2} \mathrm{O}$ and hole-doped $\mathrm{BaTi}_{2} \mathrm{Sb}_{2} \mathrm{O}$ are summarized in Table 2, where two kinds of the parameters are listed for $\mathrm{BaTi}_{2} \mathrm{Sb}_{2} \mathrm{O}$ since that of $\mathrm{BaTi}_{2} \mathrm{Sb}_{2} \mathrm{O}$ are reported in different studies. In $\left(\mathrm{Ba}_{1-x} A_{x}\right) \mathrm{Ti}_{2} \mathrm{Sb}_{2} \mathrm{O}$, the Sommerfeld constant $\gamma$ is almost the same as $\mathrm{BaTi}_{2} \mathrm{Sb}_{2} \mathrm{O}$, and the Debye temperature $\theta_{D}$ is slightly lower than that of $\mathrm{BaTi}_{2} \mathrm{Sb}_{2} \mathrm{O}$. In contrast, in $\mathrm{BaTi}_{2}\left(\mathrm{Sb}_{1-x} \mathrm{Sn}_{x}\right)_{2} \mathrm{O}$, both $\gamma$ and $\theta_{D}$ is higher than those of $\mathrm{BaTi}_{2} \mathrm{Sb}_{2} \mathrm{O}$. Gooch et al. found the excellent agreement of the electronic specific heat data with the BCS theory in $\left(\mathrm{Ba}_{0.85} \mathrm{Na}_{0.15}\right) \mathrm{Ti}_{2} \mathrm{Sb}_{2} \mathrm{O}$. Likewise, for all dopant, a ratio $\Delta C / \gamma T_{\mathrm{C}}$ is close to the standard weak-coupling BCS value 1.43, suggesting conventional superconductivity in these compounds.

Table 2. Superconducting parameters of non-doped $\mathrm{BaTi}_{2} \mathrm{Sb}_{2} \mathrm{O}$ and hole-doped $\mathrm{BaTi}_{2} \mathrm{Sb}_{2} \mathrm{O}$.

\begin{tabular}{|c|c|c|c|c|c|c|c|}
\hline Compound & $T_{\mathrm{c}}(\mathrm{K})$ & $\underset{\left(\mathrm{mJ} \cdot \mathrm{mol}^{-1} \cdot \mathrm{K}^{-2}\right)}{\gamma}$ & $\theta_{D}(\mathrm{~K})$ & $\Delta C / \gamma T_{\mathrm{c}}$ & $\mu_{0} H_{\mathrm{c} 1}(0)(\mathrm{Oe})$ & $\mu_{0} H_{\mathrm{c} 2}(0)(\mathrm{T})$ & Ref. \\
\hline $\mathrm{BaTi}_{2} \mathrm{Sb}_{2} \mathrm{O}$ & 1.2 & 13.5 & 239 & 1.36 & $\mathrm{~N} / \mathrm{A}$ & 1.32 & {$[15,39]$} \\
\hline $\mathrm{BaTi}_{2} \mathrm{Sb}_{2} \mathrm{O}$ & 1.1 & 10.9 & 230 & 0.9 & $\mathrm{~N} / \mathrm{A}$ & 0.08 & [36] \\
\hline$\left(\mathrm{Ba}_{0.85} \mathrm{Na}_{0.15}\right) \mathrm{Ti}_{2} \mathrm{Sb}_{2} \mathrm{O}$ & 4.2 & 13.0 & 210 & 1.43 & $\mathrm{~N} / \mathrm{A}$ & 1.7 & [36] \\
\hline$\left(\mathrm{Ba}_{0.8} \mathrm{Rb}_{0.2}\right) \mathrm{Ti}_{2} \mathrm{Sb}_{2} \mathrm{O}$ & 5.4 & 14 & 193 & 1.60 & 38 & 2.3 & [54] \\
\hline $\mathrm{BaTi}_{2}\left(\mathrm{Sb}_{0.9} \mathrm{Sn}_{0.1}\right)_{2} \mathrm{O}$ & 2.3 & 17.1 & 257 & 1.39 & N/A & $\mathrm{N} / \mathrm{A}$ & [55] \\
\hline
\end{tabular}

In contrast to these hole-doped systems, electron-doped systems have not been found in $\mathrm{BaTi}_{2} \mathrm{Sb}_{2} \mathrm{O}$, implying the difficulty of electron doping. Indeed, all of our attempts to synthesize electron-doped systems, such as $\left(\mathrm{Ba}_{1-x} \mathrm{La}_{x}\right) \mathrm{Ti}_{2} \mathrm{Sb}_{2} \mathrm{O}$ and $\mathrm{BaTi}_{2}\left(\mathrm{Sb}_{1-x} \mathrm{Te}_{x}\right)_{2} \mathrm{O}$, have failed. In contrast, in $\mathrm{BaTi}_{2} \mathrm{As}_{2} \mathrm{O}$, electron doping by $\mathrm{Li}^{+}$intercalation has been reported as mentioned above. Recently, another electron doping system, $\mathrm{Ba}\left(\mathrm{Ti}_{1-x} \mathrm{Cr}_{x}\right)_{2} \mathrm{As}_{2} \mathrm{O}$, has been synthesized where the $T_{\mathrm{DW}}$ is gradually suppressed with increasing $x$ and reaches $139 \mathrm{~K}$ at the solubility limit $(x=0.077)$ but no superconductivity is emerged [56]. These results may suggest electron-doping is not suitable for the superconductivity in titanium pnictide oxides. Though no superconductivity has been found in $\mathrm{BaTi}_{2} \mathrm{As}_{2} \mathrm{O}$ and its electron-doped systems, hole doping may be interesting since the hole-doped $\mathrm{BaTi}_{2} \mathrm{Sb}_{2} \mathrm{O}$ exhibits the suppression of DW instability and enhancement of $T_{\mathrm{c}}$, as discussed above.

\subsection{Substitution Effect on Other Titanium Pnictide Oxides}

A Bi analogue of $\left(\mathrm{SrF}_{2} \mathrm{Ti}_{2} \mathrm{Sb}_{2} \mathrm{O}\right.$ and $\mathrm{Na}_{2} \mathrm{Ti}_{2} \mathrm{Sb}_{2} \mathrm{O}$ might further suppress the $\mathrm{DW}$ instability and lead to superconductivity, like $\mathrm{BaTi}_{2} \mathrm{Sb}_{2} \mathrm{O}$ and $\mathrm{BaTi}_{2} \mathrm{Bi}_{2} \mathrm{O}$. Hence, we prepared a novel compound $(\mathrm{SrF})_{2} \mathrm{Ti}_{2} \mathrm{Bi}_{2} \mathrm{O}$ by the conventional solid-state reaction. The structural refinement of synchrotron XRD 
and neutron diffraction data at room temperature revealed the structure is isostructual with As and $\mathrm{Sb}$ analogues. The lattice parameters of $(\mathrm{SrF})_{2} \mathrm{Ti}_{2} \mathrm{Bi}_{2} \mathrm{O}$ are $a=4.11782(2) \AA$ and $c=21.3703(2) \AA$ from $\mathrm{XRD}$, and $a=4.11720(9) \AA$ and $c=21.3707(7) \AA$ from neutron diffraction [16]. Compared with the $\mathrm{Sb}$ analogue ( $a=4.1095(1) \AA, c=20.8858(5) \AA$ ), the $c$-axis is significantly elongated, whereas the $a$-axis is slightly elongated, whose trend is similar to those in $\mathrm{BaTi}_{2} \mathrm{Pn}_{2} \mathrm{O}$. In analogy with the replacement of $\mathrm{Sb}$ by $\mathrm{Bi}$ in $\mathrm{BaTi}_{2} \mathrm{Pn}_{2} \mathrm{O}$, the DW instability is much suppressed and disappears in $\left(\mathrm{SrF}_{2} \mathrm{Ti}_{2} \mathrm{Bi}_{2} \mathrm{O}\right.$ (Figure 13). Though superconductivity is expected, no superconducting transition has been found down to $0.5 \mathrm{~K}$.

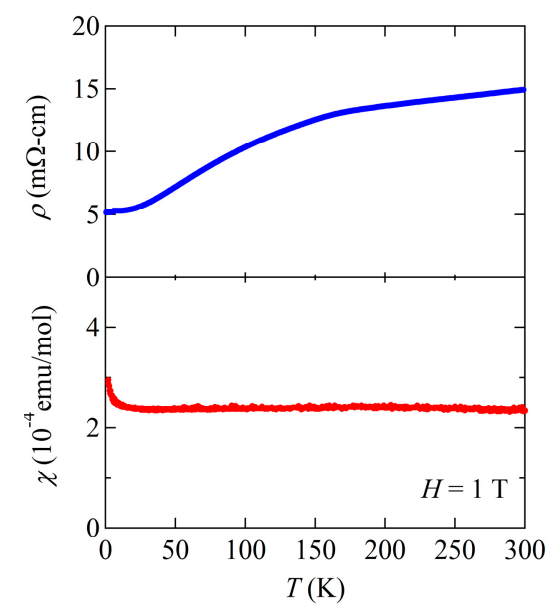

Figure 13. Temperature dependence of electrical resistivity and magnetic susceptibility under $1 \mathrm{~T}$ for $(\mathrm{SrF})_{2} \mathrm{Ti}_{2} \mathrm{Bi}_{2} \mathrm{O}$. No anomaly is observed in both data, indicating complete suppression of DW instability.

In $\mathrm{BaTi}_{2} \mathrm{Sb}_{2} \mathrm{O}$, hole doping suppresses DW instability and enhances $T_{c}$. Hence, the hole doping into $\mathrm{Na}_{2} \mathrm{Ti}_{2} \mathrm{Pn}_{2} \mathrm{O}$ and $(\mathrm{SrF})_{2} \mathrm{Ti}_{2} \mathrm{Pn}_{2} \mathrm{O}$ might also induce superconductivity. Hole doping into $\mathrm{Na}_{2} \mathrm{Ti}_{2} \mathrm{Sb}_{2} \mathrm{O}$ has been reported by Ozawa et al. where $\mathrm{Na}_{2-x} \mathrm{Ti}_{2} \mathrm{Sb}_{2} \mathrm{O}$ has been synthesized by extraction of $\mathrm{Na}^{+}$by polytetrafluoroethylene (PTFE) treatment. Though the maximum deintercalation amount $x=0.25$ is achieved, no change in $T_{\text {DW }}$ and no superconductivity have been found [57].

\section{The DW Instability in $\mathrm{BaTi}_{2} \mathrm{Pn}_{2} \mathrm{O}$}

In this section, experimental and theoretical studies on DW instability for $\mathrm{BaTi}_{2} P n_{2} \mathrm{O}$ will be discussed. The CDW/SDW has been widely observed in high- $T_{\mathrm{c}}$ cuprates and Fe-based superconductors and the relationship between DW instability and superconductivity is still under discussion. Likewise, since the DW instability competes with superconductivity in $\mathrm{BaTi}_{2} \mathrm{Pn}_{2} \mathrm{O}$, it is important to clarify the origin of DW instability to understand whether the superconductivity in $\mathrm{BaTi}_{2} \mathrm{Pn}_{2} \mathrm{O}$ is mediated by spin fluctuation or electron-phonon interaction.

In theoretical studies, both SDW and CDW instability have been suggested: the SDW instability is predicted by Singh and Wang et al. while CDW instability is predicted by Subedi and Nakano et al. [40,41,43,47]. Singh found the Fermi surface nesting which lead to peaks in susceptibility, giving rise to SDW instability. Furthermore, based on the spin-fluctuation mediated scenario, possible unconventional superconductivity was also predicted. Wang et al. calculated bare susceptibility $\chi_{0}(q)$ and found the peak of $\chi_{0}(q)$ at the $X$ point, which induces the SDW instability. Two degenerated antiferromagnetism, bi-collinear antiferromagnetism and blocked checkerboard antiferromagnetism, are suggested as the ground state. In contrast, Subedi calculated phonon dispersion and electron-phonon coupling and found a lattice instability which gives rise to a CDW instability. The $\sqrt{ } 2 \times \sqrt{ } 2 \times 1$ superstructure is predicted in the CDW phase. Nakano et al. also found that the phonon instability around the $M$ and $A$ points and predicted a $\sqrt{ } 2 \times \sqrt{ } 2 \times 1$ superstructure in both $\mathrm{BaTi}_{2} \mathrm{Sb}_{2} \mathrm{O}$ and $\mathrm{BaTi}_{2} \mathrm{Bi}_{2} \mathrm{O}$ (Figure 14). Note that they found phonon instabilities at the $X$ and $R$ points in $\mathrm{BaTi}_{2} \mathrm{As}_{2} \mathrm{O}$, which is different from $\mathrm{BaTi}_{2} \mathrm{Sb}_{2} \mathrm{O}$ and $\mathrm{BaTi}_{2} \mathrm{Bi}_{2} \mathrm{O}$. 


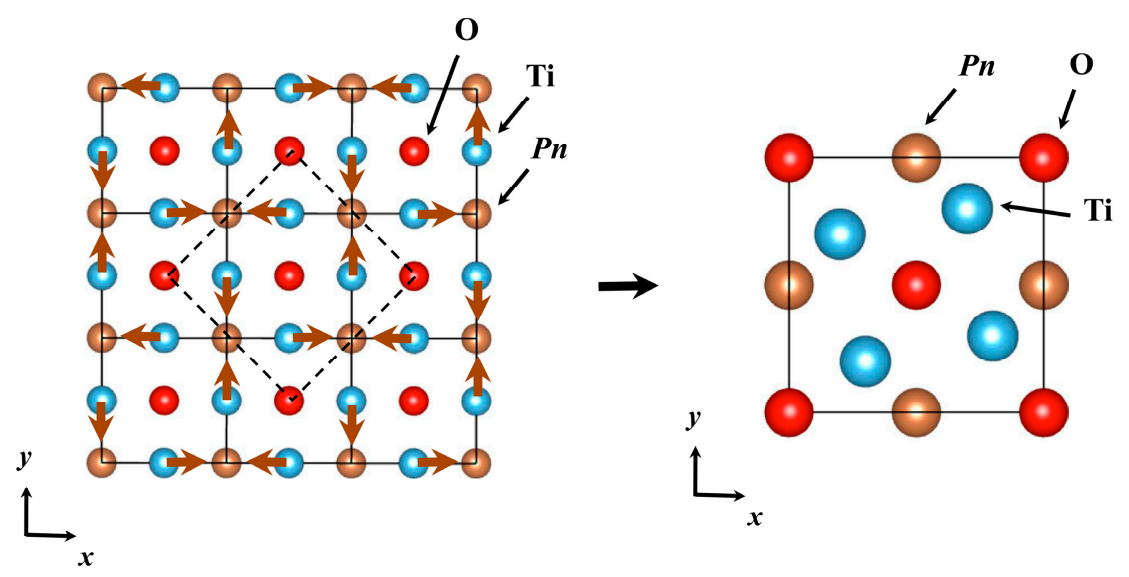

Figure 14. Atomic displacements corresponding to the imaginary phonon mode at the $M(1 / 2,1 / 2,0)$ point, leading to a $\sqrt{ } 2 \times \sqrt{ } 2 \times 1$ superlattice for $\mathrm{BaTi}_{2} \mathrm{Pn}_{2} \mathrm{O}(\mathrm{Pn}=\mathrm{Sb}$ and $\mathrm{Bi})$. Dashed lines in the left panel indicate the unit cell of the superlattice, drawn in the right panel again with displaced atomic positions after the rotation by 45 degree, which is consistent with results predicted by Subedi. The symmetry of the superlattice is $P 4 / \mathrm{mbm}$ (No. 127). Reprinted with permission from Nakano et al., Sci. Rep.; published by NPG, 2016 [43].

Experimentally, the ${ }^{121 / 123} \mathrm{Sb}-\mathrm{NQR} / \mathrm{NMR}$ spectra revealed the asymmetry parameter $\eta$ becomes finite at $4.2 \mathrm{~K}$ without the internal field, indicating the breaking of the in-plane four-fold symmetry [37]. Furthermore, the spectra does not exhibit splitting and broadening, indicating that an incommensurate DW state is excluded. The $\mu \mathrm{SR}$ measurements exclude SDW instability. Figure 15 shows time dependence of asymmetry spectra for $\mathrm{BaTi}_{2} \mathrm{As}_{2} \mathrm{O}\left(T_{\mathrm{DW}}=200 \mathrm{~K}\right)$ and $\mathrm{BaTi}_{2} \mathrm{Sb}_{2} \mathrm{O}\left(T_{D W}=50 \mathrm{~K}\right)$ [38]. The increased relaxation of the polarization could not be found below $T_{\mathrm{DW}}$, indicating the absence of magnetic order. Frandsen et al. performed low-temperature neutron diffraction measurements and found tiny lattice distortions from tetragonal to orthorhombic where the orthorhombicity parameter $\eta=2 \times(a-b) /(a+b)$ reaches only $0.22 \%$ and $0.05 \%$ at $20 \mathrm{~K}$ for $\mathrm{BaTi}_{2} \mathrm{As}_{2} \mathrm{O}$ and $\mathrm{BaTi}_{2} \mathrm{Sb}_{2} \mathrm{O}$, respectively [19]. The lattice distortion is much smaller than that observed in Jahn-Teller compounds and iron pnictides. Though a $\sqrt{ } 2 \times \sqrt{ } 2 \times 1$ superlattice was predicted in the theoretical study, no superlattice has been found in the diffraction studies. To account for the results, intra-unit-cell nematic charge order was proposed, such as that proposed in cuprates [58,59]. Recently, Song et al. reported direct observation of the CDW order with the wave vector of $(\pi, \pi)$ by STM measurements on $\mathrm{Ba}_{0.95} \mathrm{Na}_{0.05} \mathrm{Ti}_{2} \mathrm{Sb}_{2} \mathrm{O}$ (Figure 16), which is consistent with that theoretically predicted by Subedi and Nakano et al. [46]. They also performed ARPES measurements and revealed the Fermi surface is well nested along the $(\pi, \pi)$ direction, which is consistent with STM study, suggesting the electron-phonon mediated superconductivity in $\mathrm{Ba}_{0.95} \mathrm{Na}_{0.05} \mathrm{Ti}_{2} \mathrm{Sb}_{2} \mathrm{O}$. The discrepancy between the absence of the superstructure in neutron scattering and the CDW order with the wave vector of $(\pi, \pi)$ in STM and ARPES is not clear yet. Since both STM and ARPES is surface-sensitive technique, these results might not reflect bulk CDW instability due to the surface reconstruction. To unveil the nature of CDW instability in titanium pnictide oxides, the more extensive studies are required. 
(a)

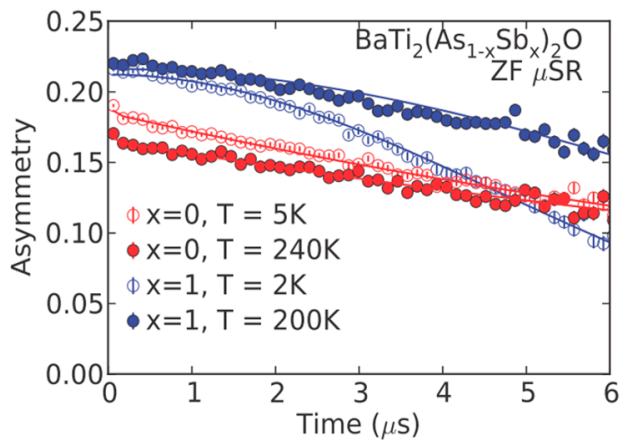

(b)

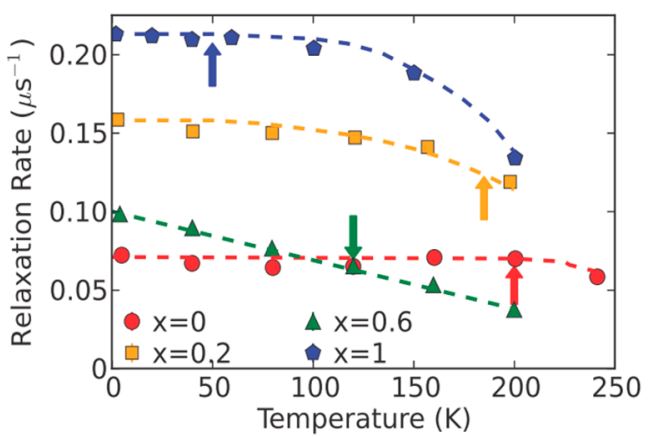

Figure 15. Results of zero-field muon spin relaxation measurements on $\mathrm{BaTi}_{2}\left(\mathrm{As}_{1-x} \mathrm{Sb}_{x}\right)_{2} \mathrm{O}$. (a) Time dependence of asymmetry for $\mathrm{BaTi}_{2} \mathrm{As}_{2} \mathrm{O}$ and $\mathrm{BaTi}_{2} \mathrm{Sb}_{2} \mathrm{O}$, indicating a slight increase in the relaxation rate at low temperatures; $(\mathbf{b})$ refined relaxation rate for $x=0,0.2,0.6,1$, where the arrow indicates the $T_{\text {DW }}$. Reprinted with permission from Nozaki et al., Phys. Rev. B; published by APS, 2013 [38].

(a)

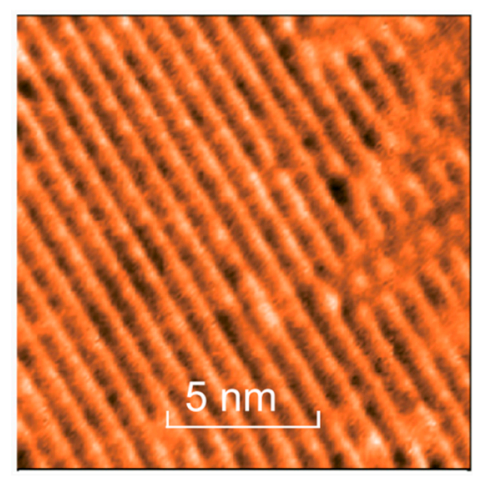

(b)

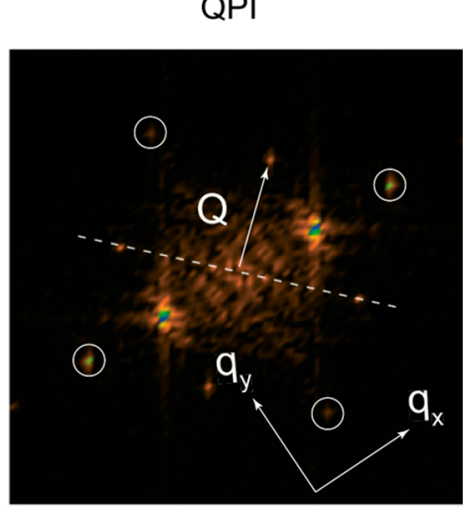

Figure 16. (a) The differential conductance map taken with the bias voltage of $-100 \mathrm{mV}$; (b) the corresponding Fourier transform of panel (a), giving a quasiparticle interference (QPI) plot. The four circled points are the lattice Bragg spots. Though the two bright points represent the $2 \times 1$ reconstruction of Ba atoms, additional weak peaks can be observed. Reprinted with permission from Song et al., Phys. Rev. B; published by APS, 2016 [46].

\section{Conclusions}

Since their discovery in 1990, titanium pnictide oxides, $A \operatorname{Ti}_{2} \mathrm{Pn}_{2} \mathrm{O}$, have attracted attention due to their structural similarity to high- $T_{\mathrm{c}}$ cuprates and Fe-based superconductors. Similar to these high- $T_{\mathrm{c}}$ superconductors, the DW instability has been found in $P n=A s, S b$ compounds. In 2012, we synthesized a new compound $\mathrm{BaTi}_{2} \mathrm{Sb}_{2} \mathrm{O}$ which exhibits superconducting transition at $1.2 \mathrm{~K}$. Following $\mathrm{BaTi}_{2} \mathrm{Sb}_{2} \mathrm{O}$, another superconductor $\mathrm{BaTi}_{2} \mathrm{Bi}_{2} \mathrm{O}\left(T_{\mathrm{c}}=4.6 \mathrm{~K}\right)$ has also been synthesized. To clarify the mechanism of superconductivity, DW instability has also been experimentally and theoretically studied. In early studies, possible SDW instability has been suggested. In contrast, recent results suggest that the DW instability is CDW. However, several phenomena have not been addressed: the mechanism of superconductivity in $\mathrm{BaTi}_{2} \mathrm{Bi}_{2} \mathrm{O}$, large MR observed below $T_{\mathrm{DW}}$, and the enhancement of magnetic fluctuations at around $T_{\mathrm{DW}}$ observed in ${ }^{121 / 123} \mathrm{Sb}-\mathrm{NQR}$ measurements. Nakaoka et al. recently predicted the formation of orbital ordering with $q=(0,0,0)$, i.e., intra-unit-cell orbital order, which may account the magnetic fluctuation around $T_{\mathrm{DW}}$ [43].

Recently, various $A \mathrm{Ti}_{2} \mathrm{Pn}_{2} \mathrm{O}$-related compounds, such as pnictide oxides and chalcogenide oxides, have been found [60-64]. For instance, $\mathrm{Ba}_{2} \mathrm{Ti}_{2} \mathrm{Fe}_{2} \mathrm{As}_{4} \mathrm{O}$ is an intergrowth of $\mathrm{BaTi}_{2} \mathrm{As}_{2} \mathrm{O}$ and $\mathrm{BaFe}_{2} \mathrm{As}_{2}$ where $T_{\mathrm{DW}}$ of $120 \mathrm{~K}$ is observed, which is lower than that in $\mathrm{BaTi}_{2} \mathrm{As}_{2} \mathrm{O}$ due to the interlayer charge 
transfer [60]. Both $\mathrm{CsV}_{2} \mathrm{~S}_{2} \mathrm{O}$ and $\mathrm{Cs}_{1-x} \mathrm{Ti}_{2} \mathrm{Te}_{2} \mathrm{O}$ have the same structure as $\mathrm{BaTi}_{2} \mathrm{Pn}_{2} \mathrm{O}$, but they do not show any DW instability, while they show bad-metal and metallic conduction, respectively [61,62]. Though no superconductor has been found in $A \mathrm{Ti}_{2} \mathrm{Pn}_{2} \mathrm{O}$-related compounds yet, the discovery of superconductivity in titanium pnictide oxides might give rise to new classes of superconductors, just as cuprates and Fe-based superconductors have given rise.

Acknowledgments: The author gratefully acknowledge the support from JSPS KAKENHI Grant Number 15K17698.

Conflicts of Interest: The authors declare no conflict of interest.

\section{References}

1. Bednorz, J.G.; Müller, K.A. Possible high $T_{\mathrm{C}}$ superconductivity in the Ba-La-Cu-O system. Z. Phys. B 1986, 64, 189-193. [CrossRef]

2. Nagamatsu, J.; Nakagawa, N.; Muranaka, T.; Zenitani, Y.; Akimitsu, J. Superconductivity at $39 \mathrm{~K}$ in magnesium diboride. Nature 2001, 410, 63-64. [CrossRef] [PubMed]

3. Yamanaka, S.; Hotehama, K.I.; Kawaji, H. Superconductivity at $25.5 \mathrm{~K}$ in electron-doped layered hafnium nitride. Nature 1998, 392, 580-582. [CrossRef]

4. Maeno, Y.; Hashimoto, H.; Yoshida, K.; Nishizaki, S.; Fujita, T.; Bednorz, J.G.; Lichtenberg, F. Superconductivity in a layered perovskite without copper. Nature 1994, 372, 532-534. [CrossRef]

5. Takada, K.; Sakurai, H.; Takayama-Muromachi, E.; Izumi, F.; Dilanian, R.A.; Sasaki, T. Superconductivity in two-dimensional $\mathrm{CoO}_{2}$ layers. Nature 2003, 422, 53-55. [CrossRef] [PubMed]

6. Kamihara, Y.; Watanabe, T.; Hirano, M.; Hosono, H. Iron-Based Layered Superconductor $\operatorname{La}\left(\mathrm{O}_{1-x} \mathrm{~F}_{x}\right) \mathrm{Fe} A s$ $(x=0.05-0.12)$ with $T_{\mathrm{C}}=26$ K. J. Am. Chem. Soc. 2008, 130, 3296-3297. [CrossRef] [PubMed]

7. Mizuguchi, Y.; Demura, S.; Deguchi, K.; Takano, Y.; Fujihisa, H.; Gotoh, Y.; Izawa, H.; Miura, O. Superconductivity in Novel $\mathrm{BiS}_{2}$-Based Layered Superconductor $\mathrm{LaO}_{1-x} \mathrm{~F}_{x} \mathrm{BiS}_{2}$. J. Phys. Soc. Jpn. 2012, 81, 114725. [CrossRef]

8. Hor, Y.S.; Williams, A.J.; Checkelsky, J.G.; Roushan, P.; Seo, J.; Xu, Q.; Zandbergen, H.W.; Yazdani, A.; Ong, N.P.; Cava, R.J. Superconductivity in $\mathrm{Cu}_{x} \mathrm{Bi}_{2} \mathrm{Se}_{3}$ and its implications for pairing in the undoped topological insulator. Phys. Rev. Lett. 2010, 104, 057001. [CrossRef] [PubMed]

9. Pyon, S.; Kudo, K.; Nohara, M. Superconductivity induced by bond breaking in the triangular lattice of $\operatorname{IrTe}_{2}$. J. Phys. Soc. Jpn. 2012, 81, 053701. [CrossRef]

10. Kudo, K.; Ishii, H.; Takasuga, M.; Iba, K.; Nakano, S.; Kim, J.; Fujiwara, A.; Nohara, M. Superconductivity Induced by Breaking Te 2 Dimers of AuTe 2 . J. Phys. Soc. Jpn. 2013, 82, 063704. [CrossRef]

11. Adam, A.; Schuster, H.-U. Darstellung und Kristallstruktur der Pnictidoxide $\mathrm{Na}_{2} \mathrm{Ti}_{2} \mathrm{As}_{2} \mathrm{O}$ und $\mathrm{Na}_{2} \mathrm{Ti}_{2} \mathrm{Sb}_{2} \mathrm{O}$. ZAAC 1990, 584, 150-158. (In German) [CrossRef]

12. Morosan, E.; Zandbergen, H.W.; Dennis, B.S.; Bos, J.W.G.; Onose, Y.; Klimczuk, T.; Ramirez, A.P.; Ong, N.P.; Cava, R.J. Superconductivity in $\mathrm{Cu}_{x} \mathrm{TiSe}_{2}$. Nat. Phys. 2006, 2, 544-550. [CrossRef]

13. Wu, W.; Cheng, J.; Matsubayashi, K.; Kong, P.; Lin, F.; Jin, C.; Wang, N.; Uwatoko, Y.; Luo, J. Superconductivity in the vicinity of antiferromagnetic order in CrAs. Nat. Commun. 2014, 5, 5508. [CrossRef] [PubMed]

14. Wang, X.F.; Yan, Y.J.; Ying, J.J.; Li, Q.J.; Zhang, M.; Xu, N.; Chen, X.H. Structure and physical properties for a new layered pnictide-oxide: $\mathrm{BaTi}_{2} \mathrm{As}_{2} \mathrm{O}$. J. Phys. Condens. Matter 2010, 22, 075702. [CrossRef]

15. Yajima, T.; Nakano, K.; Takeiri, F.; Ono, T.; Hosokoshi, Y.; Matsushita, Y.; Hester, J.; Kageyama, H. Superconductivity in $\mathrm{BaTi}_{2} \mathrm{Sb}_{2} \mathrm{O}$ with a $d^{1}$ square lattice. J. Phys. Soc. Jpn. 2012, 81, 103706. [CrossRef]

16. Yajima, T.; Nakano, K.; Takeiri, F.; Hester, J.; Yamamoto, T.; Kobayashi, Y.; Tsuji, N.; Kim, J.; Fujiwara, A.; Kageyama, H. Synthesis and physical properties of the new oxybismuthides $\mathrm{BaTi}_{2} \mathrm{Bi}_{2} \mathrm{O}$ and $\left(\mathrm{SrF}_{2} \mathrm{Ti}_{2} \mathrm{Bi}_{2} \mathrm{O}\right.$ with a $d^{1}$ square net. J. Phys. Soc. Jpn. 2012, 82, 013703. [CrossRef]

17. Liu, R.H.; Song, Y.A.; Li, Q.J.; Ying, J.J.; Yan, Y.J.; He, Y.; Chen, X.H. Structure and Physical Properties of the Layered Pnictide-Oxides: $(\mathrm{SrF})_{2} \mathrm{Ti}_{2} \mathrm{Pn}_{2} \mathrm{O}(\mathrm{Pn}=\mathrm{As}, \mathrm{Sb})$ and $(\mathrm{SmO})_{2} \mathrm{Ti}_{2} \mathrm{Sb}_{2} \mathrm{O}$. Chem. Mater. 2010, 22, 1503-1508. [CrossRef]

18. Yajima, T.; Nakano, K.; Takeiri, F.; Nozaki, Y.; Kobayashi, Y.; Kageyama, H. Two Superconducting Phases in the Isovalent Solid Solutions $\mathrm{BaTi}_{2} \mathrm{Pn}_{2} \mathrm{O}$ (Pn = As, Sb, and Bi). J. Phys. Soc. Jpn. 2013, 82, 033705. [CrossRef] 
19. Frandsen, B.A.; Bozin, E.S.; Hu, H.; Zhu, Y.; Nozaki, Y.; Kageyama, H.; Uemura, Y.J.; Yinm, W.G.; Billinge, S.J. Intra-unit-cell nematic charge order in the titanium-oxypnictide family of superconductors. Nat. Commun. 2014, 5, 5761. [CrossRef] [PubMed]

20. Deslandes, F.; Nazzal, A.I.; Torrance, J.B. Search for superconductivity in analogues of $\mathrm{La}_{2-x} \mathrm{Sr}_{x} \mathrm{CuO}_{4}$ : $\mathrm{Sr}_{2-x} \mathrm{Ln}_{x} \mathrm{VO}_{4}(\mathrm{Ln}=\mathrm{La}, \mathrm{Ce}, \mathrm{Pr}, \mathrm{Nd}, \mathrm{Eu})$. Physica C 1991, 179, 85-90. [CrossRef]

21. Arita, R.; Yamasaki, A.; Held, K.; Matsuno, J.; Kuroki, K. $\mathrm{Sr}_{2} \mathrm{VO}_{4}$ and $\mathrm{Ba}_{2} \mathrm{VO}_{4}$ under pressure: An orbital switch and potential $d^{1}$ superconductor. Phys. Rev. B 2007, 75, 174521. [CrossRef]

22. Axtell, E.A.; Ozawa, T.; Kauzlarich, S.M.; Singh, R.R. Phase transition and spin-gap behavior in a layered tetragonal pnictide oxide. J. Solid State Chem. 1997, 134, 423-426. [CrossRef]

23. Shi, Y.G.; Wang, H.P.; Zhang, X.; Wang, W.D.; Huang, Y.; Wang, N.L. Strong anisotropy in the electromagnetic properties of $\mathrm{Na}_{2} \mathrm{Ti}_{2} \mathrm{X}_{2} \mathrm{O}(\mathrm{X}=\mathrm{As}, \mathrm{Sb})$ crystals. Phys. Rev. B 2013, 88, 144513. [CrossRef]

24. Pickett, W.E. Electronic instability in inverse- $\mathrm{K}_{2} \mathrm{NiF}_{4}$-structure $\mathrm{Na}_{2} \mathrm{Sb}_{2} \mathrm{Ti}_{2}$ O. Phys. Rev. B 1998, 58, $4335-4340$. [CrossRef]

25. Fabrizi de Biani, F.; Alemany, P.; Canadell, E. Concerning the Resistivity Anomaly in the Layered Pnictide Oxide $\mathrm{Na}_{2} \mathrm{Ti}_{2} \mathrm{Sb}_{2} \mathrm{O}$. Inorg. Chem. 1998, 37, 5807-5810. [CrossRef]

26. Ozawa, T.C.; Pantoja, R.; Axtell, E.A.; Kauzlarich, S.M.; Greedan, J.E.; Bieringer, M.; Richardson, J.W. Powder Neutron Diffraction Studies of $\mathrm{Na}_{2} \mathrm{Ti}_{2} \mathrm{Sb}_{2} \mathrm{O}$ and Its Structure-Property Relationships. J. Solid State Chem. 2000, 153, 275-281. [CrossRef]

27. Liu, R.H.; Tan, D.; Song, Y.A.; Li, Q.J.; Yan, Y.J.; Ying, J.J.; Xie, Y.L.; Wang, X.F.; Chen, X.H. Physical properties of the layered pnictide oxides $\mathrm{Na}_{2} \mathrm{Ti}_{2} P_{2} \mathrm{O}$ ( $P=$ As, Sb). Phys. Rev. B 2009, 80, 144516. [CrossRef]

28. Ozawa, T.C.; Kauzlarich, S.M. Single crystal growth and characterization of a layered transition metal pnictide oxide: $\mathrm{Na}_{2} \mathrm{Ti}_{2} \mathrm{Sb}_{2} \mathrm{O}$. J. Cryst. Growth 2004, 265, 571-576. [CrossRef]

29. Song, Y.J.; Ghim, J.S.; Min, B.H.; Kwon, Y.S.; Jung, M.H.; Rhyee, J.S. Synthesis, anisotropy, and superconducting properties of LiFeAs single crystal. Appl. Phys. Lett. 2010, 96, 212508. [CrossRef]

30. Tanatar, M.A.; Ni, N.; Samolyuk, G.D.; Bud'ko, S.L.; Canfield, P.C.; Prozorov, R. Resistivity anisotropy of $A \mathrm{Fe}_{2} \mathrm{As}_{2}(A=\mathrm{Ca}, \mathrm{Sr}, \mathrm{Ba})$ : Direct versus Montgomery technique measurements. Phys. Rev. B 2009, 79, 134528. [CrossRef]

31. Jesche, A.; Nitsche, F.; Probst, S.; Doert, Th.; Müller, P.; Ruck, M. Anisotropic electrical resistivity of LaFeAsO: Evidence for electronic nematicity. Phys. Rev. B 2012, 86, 134511. [CrossRef]

32. Suetin, D.V.; Ivanovskii, A.L. Structural, electronic properties, and chemical bonding in quaternary layered titanium pnictide-oxides $\mathrm{Na}_{2} \mathrm{Ti}_{2} \mathrm{Pn}_{2} \mathrm{O}$ and $\mathrm{BaTi}_{2} \mathrm{Pn}_{2} \mathrm{O}(\mathrm{Pn}=\mathrm{As}, \mathrm{Sb})$ from FLAPW-GGA calculations. J. Alloy Compd. 2013, 564, 117-124. [CrossRef]

33. Doan, P.; Gooch, M.; Tang, Z.; Lorenz, B.; Möller, A.; Tapp, J.; Chu, P.C.W.; Guloy, A.M. Ba ${ }_{1-x} \mathrm{Na}_{x} \mathrm{Ti}_{2} \mathrm{Sb}_{2} \mathrm{O}$ $(0.0 \leq x \leq 0.33)$ : A Layered Titanium-Based Pnictide Oxide Superconductor. J. Am. Chem. Soc. 2012, 134, 16520-16523. [CrossRef] [PubMed]

34. Kasahara, S.; Shibauchi, T.; Hashimoto, K.; Ikada, K.; Tonegawa, S.; Okazaki, R.; Shishido, H.; Ikeda, H.; Takeya, H.; Hirata, K.; et al. Evolution from non-Fermi-to Fermi-liquid transport via isovalent doping in $\mathrm{BaFe}_{2}\left(\mathrm{As}_{1-x} \mathrm{P}_{x}\right)_{2}$ superconductors. Phys. Rev. B 2010, 81, 184519. [CrossRef]

35. Hoffmann, R.; Zheng, C. Making and Breaking Bonds in the Solid State: The $\mathrm{ThCr}_{2} \mathrm{Si}_{2} \mathrm{Structure}$ J. Phys. Chem. 1985, 89, 4175-4181. [CrossRef]

36. Gooch, M.; Doan, P.; Tang, Z.; Lorenz, B.; Guloy, A.M.; Chu, P.C. Weak coupling BCS-like superconductivity in the pnictide oxide $\mathrm{Ba}_{1-x} \mathrm{Na}_{x} \mathrm{Ti}_{2} \mathrm{Sb}_{2} \mathrm{O}$ ( $x=0$ and 0.15). Phys. Rev. B 2013, 88, 064510. [CrossRef]

37. Kitagawa, S.; Ishida, K.; Nakano, K.; Yajima, T.; Kageyama, H. s-wave superconductivity in superconducting $\mathrm{BaTi}_{2} \mathrm{Sb}_{2} \mathrm{O}$ revealed by ${ }^{121 / 123} \mathrm{Sb}-\mathrm{NMR} /$ nuclear quadrupole resonance measurements. Phys. Rev. B 2013, 87, 060510. [CrossRef]

38. Nozaki, Y.; Nakano, K.; Yajima, T.; Kageyama, H.; Frandsen, B.; Liu, L.; Cheung, S.; Goko, T.; Uemura, Y.J.; Munsie, T.S.J.; et al. Muon spin relaxation and electron/neutron diffraction studies of $\mathrm{BaTi}_{2}\left(\mathrm{As}_{1-x} \mathrm{Sb}_{x}\right)_{2} \mathrm{O}$ : Absence of static magnetism and superlattice reflections. Phys. Rev. B 2013, 88, 214506. [CrossRef]

39. Yajima, T.; Nakano, K.; Nozaki, Y.; Kageyama, H. Superconducting properties of $\mathrm{BaTi}_{2} \mathrm{Pn}_{2} \mathrm{O}(\mathrm{Pn}=\mathrm{Sb}, \mathrm{Bi})$. Physica C 2014, 504, 36-38. [CrossRef]

40. Singh, D.J. Electronic structure, disconnected Fermi surfaces and antiferromagnetism in the layered pnictide superconductor $\mathrm{Na}_{x} \mathrm{Ba}_{1-x} \mathrm{Ti}_{2} \mathrm{Sb}_{2} \mathrm{O}$. New J. Phys. 2012, 14, 123003. [CrossRef] 
41. Wang, G.; Zhang, H.; Zhang, L.; Liu, C. The electronic structure and magnetism of $\mathrm{BaTi}_{2} \mathrm{Sb}_{2} \mathrm{O}$. J. Appl. Phys. 2013, 113, 243904. [CrossRef]

42. Nakaoka, H.; Yamakawa, Y.; Kontani, H. Theoretical prediction of nematic orbital-ordered state in the Ti oxypnictide superconductor $\mathrm{BaTi}_{2}(\mathrm{As}, \mathrm{Sb})_{2} \mathrm{O}$. Phys. Rev. B 2016, 93, 245122. [CrossRef]

43. Nakano, K.; Hongo, K.; Maezono, R. Phonon dispersions and Fermi surfaces nesting explaining the variety of charge ordering in titanium-oxypnictides superconductors. Sci. Rep. 2016, 6, 29661. [CrossRef] [PubMed]

44. Suetin, D.V.; Ivanovskii, A.L. Electronic properties and fermi surface for new Fe-free layered pnictide-oxide superconductor $\mathrm{BaTi}_{2} \mathrm{Bi}_{2} \mathrm{O}$ from first principles. JETP Lett. 2013, 97, 220-225. [CrossRef]

45. Yan, X.W.; Lu, Z.Y. Layered pnictide-oxide $\mathrm{Na}_{2} \mathrm{Ti}_{2} \mathrm{Pn}_{2} \mathrm{O}(\mathrm{Pn}=\mathrm{As}, \mathrm{Sb})$ : A candidate for spin density waves. J. Phys. Condens. Matter 2013, 25, 365501. [CrossRef] [PubMed]

46. Song, Q.; Yan, Y.J.; Ye, Z.R.; Ren, M.Q.; Xu, D.F.; Tan, S.Y.; Niu, X.H.; Xie, B.P.; Zhang, T.; Peng, R.; et al. Electronic structure of the titanium-based oxypnictide superconductor $\mathrm{Ba}_{0.95} \mathrm{Na}_{0.05} \mathrm{Ti}_{2} \mathrm{Sb}_{2} \mathrm{O}$ and direct observation of its charge density wave order. Phys. Rev. B 2016, 93, 024508. [CrossRef]

47. Subedi, A. Electron-phonon superconductivity and charge density wave instability in the layered titanium-based pnictide BaTi ${ }_{2} \mathrm{Sb}_{2}$ O. Phys. Rev. B 2013, 87, 054506. [CrossRef]

48. Zhai, H.F.; Jiao, W.H.; Sun, Y.L.; Bao, J.K.; Jiang, H.; Yang, X.J.; Tang, Z.T.; Tao, Q.; Xu, X.F.; Li, Y.K.; et al. Superconductivity, charge-or spin-density wave, and metal-nonmetal transition in $\mathrm{BaTi}_{2}\left(\mathrm{Sb}_{1-x} \mathrm{Bi}_{x}\right)_{2} \mathrm{O}$. Phys. Rev. B 2013, 87, 100502. [CrossRef]

49. Hiraishi, M.; Iimura, S.; Kojima, K.M.; Yamaura, J.; Hiraka, H.; Ikeda, K.; Miao, P.; Ishikawa, Y.; Torii, S.; Miyazaki, M.; et al. Bipartite magnetic parent phases in the iron oxypnictide superconductor. Nat. Phys. 2014, 10, 300-303. [CrossRef]

50. Mukuda, H.; Engetsu, F.; Yamamoto, K.; Lai, K.T.; Yashima, M.; Kitaoka, Y.; Takemori, A.; Miyasaka, S.; Tajima, S. Enhancement of superconducting transition temperature due to antiferromagnetic spin fluctuations in iron pnictides $\mathrm{LaFe}\left(\mathrm{As}_{1-x} \mathrm{P}_{\mathrm{x}}\right)\left(\mathrm{O}_{1-y} \mathrm{~F}_{y}\right)$ : ${ }^{31} \mathrm{P}-\mathrm{NMR}$ studies. Phys. Rev. B 2014, 89, 064511. [CrossRef]

51. Matsuishi, S.; Maruyama, T.; limura, S.; Hosono, H. Controlling factors of Tc dome structure in 1111-type iron arsenide superconductors. Phys. Rev. B 2014, 89, 094510. [CrossRef]

52. Pachmayr, U.; Johrendt, D. Superconductivity in $\mathrm{Ba}_{1-x} \mathrm{~K}_{x} \mathrm{Ti}_{2} \mathrm{Sb}_{2} \mathrm{O}(0 \leq x \leq 1)$ controlled by the layer charge. Solid State Sci. 2014, 28, 31-34. [CrossRef]

53. Von Rohr, F.; Nesper, R.; Schilling, A. Superconductivity in rubidium-substituted $\mathrm{Ba}_{1-x} \mathrm{Rb}_{x} \mathrm{Ti}_{2} \mathrm{Sb}_{2} \mathrm{O}$. Phys. Rev. B 2014, 89, 094505. [CrossRef]

54. Nakano, K.; Yajima, T.; Takeiri, F.; Green, M.A.; Hester, J.; Kobayashi, Y.; Kageyama, H. $T_{\mathrm{c}}$ Enhancement by Aliovalent Anionic Substitution in Superconducting BaTi $2\left(\mathrm{Sb}_{1-x} \mathrm{Sn}_{x}\right)_{2}$ O. J. Phys. Soc. Jpn. 2013, 82, 074707. [CrossRef]

55. Gooch, M.; Doan, P.; Lorenz, B.; Tang, Z.J.; Guloy, A.M.; Chu, C.W. High pressure study of the normal and superconducting states of the layered pnictide oxide $\mathrm{Ba}_{1-x} \mathrm{Na}_{x} \mathrm{Ti}_{2} \mathrm{Sb}_{2} \mathrm{O}$ with $x=0,0.10$, and 0.15. Supercond. Sci. Technol. 2013, 26, 125011. [CrossRef]

56. Ji, Q.; Ma, Y.; Hu, K.; Gao, B.; Mu, G.; Li, W.; Hu, T.; Zhang, G.; Zhao, Q.; Zhang, H.; et al. Synthesis, Structural, and Transport Properties of Cr-Doped $\mathrm{BaTi}_{2} \mathrm{As}_{2} \mathrm{O}$. Inorg. Chem. 2014, 53, 13089-13092. [CrossRef] [PubMed]

57. Ozawa, T.C.; Naka, T.; Matsushita, A.; Kauzlarich, S.M.; Sasaki, T. Chemical composition and magnetic property modifications of $\mathrm{Na}_{2} \mathrm{Ti}_{2} \mathrm{Sb}_{2} \mathrm{O}$ using PTFE as an alkali-metal ion extraction reagent. J. Fluor. Chem. 2014, 168, 189-192. [CrossRef]

58. Fujita, K.; Hamidian, M.H.; Edkins, S.D.; Kim, C.K.; Kohsaka, Y.; Azuma, M.; Takano, M.; Takagi, H.; Eisaki, H.; Uchida, S.; et al. Direct phase-sensitive identification of a $d$-form factor density wave in underdoped cuprates. Proc. Natl. Acad. Sci. USA 2014, 111, E3026-E3032. [CrossRef] [PubMed]

59. Yamakawa, Y.; Kontani, H. Spin-Fluctuation-Driven Nematic Charge-Density Wave in Cuprate Superconductors: Impact of Aslamazov-Larkin Vertex Corrections. Phys. Rev. Lett. 2015, 114, 257001. [CrossRef] [PubMed]

60. Sun, Y.L.; Jiang, H.; Zhai, H.F.; Bao, J.K.; Jiao, W.H.; Tao, Q.; Shen, C.Y.; Zeng, Y.W.; Xu, Z.A.; Cao, G.H. $\mathrm{Ba}_{2} \mathrm{Ti}_{2} \mathrm{Fe}_{2} \mathrm{As}_{4} \mathrm{O}$ : A new superconductor containing $\mathrm{Fe}_{2} \mathrm{As}_{2}$ layers and $\mathrm{Ti}_{2} \mathrm{O}$ sheets. J. Am. Chem. Soc. 2012, 134, 12893-12896. [CrossRef] [PubMed]

61. Valldor, M.; Merz, P.; Prots, Y.; Schnelle, W. Bad-Metal-Layered Sulfide Oxide $\mathrm{CsV}_{2} \mathrm{~S}_{2} \mathrm{O}$. Eur. J. Inorg. Chem. 2016, 2016, 23-27. [CrossRef] 
62. Valldor, M.; Merz, P.; Prots, Y.; Watier, Y.; Schnelle, W. Synthesis and Characterization of $\mathrm{Cs}_{1-x} \mathrm{Ti}_{2} \mathrm{Te}_{2} \mathrm{O}$ $(x \approx 0.2)$ : Electron Doping by Te Resulting in a Layered Metal. Inorg. Chem. 2016, 55, 11337-11341. [CrossRef] [PubMed]

63. Mizoguchi, H.; Park, S.; Hiraka, H.; Ikeda, K.; Otomo, T.; Hosono, H. An Anti $\mathrm{CuO}_{2}$-type Metal Hydride Square Net Structure in $L n_{2} M_{2} \mathrm{As}_{2} \mathrm{H}_{x}$ ( $L n=\mathrm{La}$ or $\mathrm{Sm}, M=\mathrm{Ti}, \mathrm{V}, \mathrm{Cr}$, or Mn). Angew. Chem. Int. Ed. 2015, 54, 2932-2935. [CrossRef] [PubMed]

64. Takeiri, F.; Matsumoto, Y.; Yamamoto, T.; Hayashi, N.; Li, Z.; Tohyama, T.; Tassel, C.; Ritter, C.; Narumi, Y.; Hagiwara, M.; et al. High-pressure synthesis of the layered iron oxyselenide $\mathrm{BaFe}_{2} \mathrm{Se}_{2} \mathrm{O}$ with strong magnetic anisotropy. Phys. Rev. B 2016, 94, 184426. [CrossRef]

(C) 2017 by the author; licensee MDPI, Basel, Switzerland. This article is an open access article distributed under the terms and conditions of the Creative Commons Attribution (CC-BY) license (http://creativecommons.org/licenses/by/4.0/). 